\title{
Neural crest cell-autonomous roles of fibronectin in cardiovascular development.
}

\author{
Xia Wang \\ Thomas Jefferson University \\ Sophie Astrof \\ Thomas Jefferson University
}

Follow this and additional works at: https://jdc.jefferson.edu/medfp

Part of the Translational Medical Research Commons

Let us know how access to this document benefits you

\section{Recommended Citation}

Wang, Xia and Astrof, Sophie, "Neural crest cell-autonomous roles of fibronectin in cardiovascular development." (2016). Department of Medicine Faculty Papers. Paper 173. https://jdc.jefferson.edu/medfp/173

This Article is brought to you for free and open access by the Jefferson Digital Commons. The Jefferson Digital Commons is a service of Thomas Jefferson University's Center for Teaching and Learning (CTL). The Commons is a showcase for Jefferson books and journals, peer-reviewed scholarly publications, unique historical collections from the University archives, and teaching tools. The Jefferson Digital Commons allows researchers and interested readers anywhere in the world to learn about and keep up to date with Jefferson scholarship. This article has been accepted for inclusion in Department of Medicine Faculty Papers by an authorized administrator of the Jefferson Digital Commons. For more information, please contact: JeffersonDigitalCommons@jefferson.edu. 


\title{
Neural crest cell-autonomous roles of fibronectin in cardiovascular development
}

\author{
Xia Wang and Sophie Astrof*
}

\begin{abstract}
The chemical and mechanical properties of extracellular matrices (ECMs) modulate diverse aspects of cellular fates; however, how regional heterogeneity in ECM composition regulates developmental programs is not well understood. We discovered that fibronectin 1 (Fn1) is expressed in strikingly non-uniform patterns during mouse development, suggesting that regionalized synthesis of the ECM plays cell-specific regulatory roles during embryogenesis. To test this hypothesis, we ablated $F n 1$ in the neural crest (NC), a population of multi-potent progenitors expressing high levels of $F n 1$. We found that Fn1 synthesized by the NC mediated morphogenesis of the aortic arch artery and differentiation of NC cells into vascular smooth muscle cells (VSMCs) by regulating Notch signaling. We show that NC Fn1 signals in an NC cell-autonomous manner through integrin $\alpha 5 \beta 1$ expressed by the NC, leading to activation of Notch and differentiation of VSMCs. Our data demonstrate an essential role of the localized synthesis of Fn1 in cardiovascular development and spatial regulation of Notch signaling.
\end{abstract}

KEY WORDS: Cardiovascular development, Fibronectin, Integrin $\alpha 5 \beta 1$, Neural crest, Notch, Lateral induction, Vascular smooth muscle cells

\section{INTRODUCTION}

Aortic arch arteries (AAAs) route oxygenated blood from the heart to the rest of the body. Malformations in this vascular tree are common causes of morbidity and mortality in patients with congenital heart disease (CHD) (Go et al., 2013; Moon, 2008, 2006). Development of the AAAs occurs similarly in humans and in mice, and results from asymmetrical remodeling of the three pairs of pharyngeal arch arteries (PAAs) that are initially positioned symmetrically around the midline (Conway et al., 2003; Stoller and Epstein, 2005) (Fig. 1A,B). Animal models indicate that defective remodeling of initially well-formed, symmetrical PAAs may cause some forms of CHD, e.g. the Alagille syndrome (High and Epstein, 2008). In this syndrome, as well as in many nonsyndromic CHD patients, the AAA abnormalities stem, in part, from defects in derivatives of the 4th pair of PAAs (the left and/or the right). The left 4 th PAA gives rise to the aortic arch and the right 4 th PAA gives rise to the proximal segment of the right subclavian artery (Stoller and Epstein, 2005). Regression of the left 4th PAA results in the interrupted aortic arch, which is lethal. Regression of the right 4th PAA results in a vascular abnormality called retroesophageal right subclavian artery (RERSA), in which the

Sidney Kimmel Medical College of Thomas Jefferson University, Department of Medicine, Center for Translational Medicine, 1020 Locust Street, Philadelphia, PA 19107, USA.

*Author for correspondence (sophie.astrof@gmail.com)

Received 13 April 2015; Accepted 3 November 2015 right subclavian artery originates from the descending aorta on the left, instead of the brachiocephalic trunk on the right (Stoller and Epstein, 2005).

The development of vascular smooth muscle cells (VSMCs) around the three symmetrical pairs of PAAs is necessary to prevent premature regression of these vessels and to facilitate their asymmetrical remodeling (High et al., 2007; Hutson and Kirby, 2007; Yashiro et al., 2007). VSMCs surrounding the PAA endothelium derive from the neural crest (NC) - a population of neuroectodermal stem cells that originate along the anteriorposterior axis at the dorsal margin of the neural tube (Donoghue et al., 2008; Le Douarin and Kalcheim, 1999). NC cells detach from the neural tube and migrate extensive distances along the stereotypical paths characteristic of their axial positions of origin. Upon arrival at their destinations, NC-derived cells participate in the morphogenesis of numerous organs and differentiate into a diverse array of cell types, including neurons and glia of the peripheral nervous system, bones and cartilage of the face, melanocytes of the skin, and VSMCs of the cerebral and pharyngeal vasculature (Crane and Trainor, 2006; Le Douarin and Kalcheim, 1999). NC cells that migrate into the pharyngeal arches 3-6 and into the heart are called cardiac NC cells. The cardiac NC originates from the region of the dorsal neural tube located between the otic pit and the 4th somite (Chan et al., 2004; Hutson and Kirby, 2007).

Studies in chickens and mice show that NC cell fates are influenced by signals emanating from their host tissues (Chen et al., 2012; Donoghue et al., 2008; Ferguson and Graham, 2004; Itasaki et al., 1996; Trainor and Krumlauf, 2000; Trainor et al., 2002a,b). In the pharyngeal arches, Notch signaling from the PAA endothelium mediates differentiation of the adjacent NC cell layers into VSMCs, and the region of active Notch around the PAA endothelium corresponds to the area within which NC cells undergo VSMC differentiation (High et al., 2008, 2007; Manderfield et al., 2012). However, mechanisms that limit the activation of Notch to the few NC cell layers proximal to PAA endothelium are unknown.

In our prior work, we made the unexpected observation that fibronectin 1 (Fn1) mRNA and protein are highly enriched in distinct regions of the mouse embryo, including regions corresponding to the developing NC and the pharyngeal arches 3, 4 and 6 (Mittal et al., 2010). Interestingly, many other ECM glycoproteins are also non-uniformly distributed during embryogenesis (reviewed in Astrof, 2013; Watt and Huck, 2013). This suggests that the highly localized distribution of ECM components during embryo development generates distinct microenvironments that can influence morphogenetic events in a spatially dependent manner. To test this hypothesis, we conditionally inactivated Fn1 in the NC, and found that $\mathrm{NC}$-synthesized $\mathrm{Fn} 1$ regulates AAA morphogenesis and the differentiation of NC cells into VSMCs. Our studies indicated that NC-synthesized Fn1 regulates VSMC differentiation by facilitating Notch signal transduction from the endothelium to the adjacent NC cells. Furthermore, we found that Notch activation 

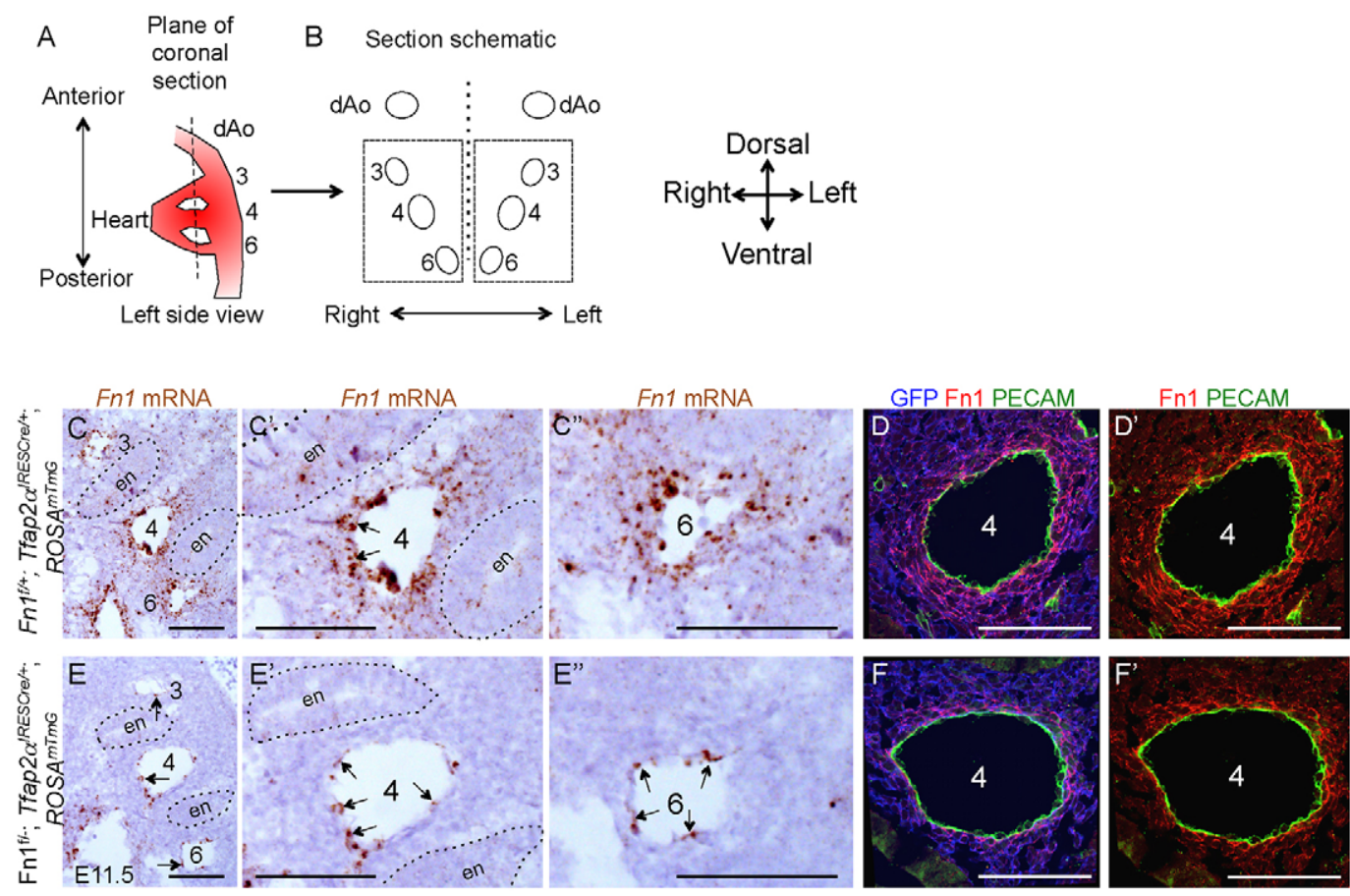

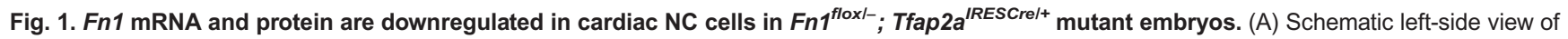
pharyngeal arch arteries 3, 4 and 6 connecting the heart with the dorsal aorta. Sections in all figures were cut along coronal planes (dotted line), the axes are marked. (B) Schematic view of a coronal section through the pharyngeal region. PAAs are numbered, axes are indicated. (C-D') Controls. (E- $\left.F^{\prime}\right)$ Mutants. (C-C" and E-E") Fn1 mRNA. In Fn1 $1^{f l o x /}$; Cre ${ }^{+}$mutants, Fn1 mRNA is downregulated in the NC but not in the PAA endothelium (arrows). Magnified views of the 4th and 6th PAAs are shown in $C^{\prime}, C^{\prime \prime}$ and $E^{\prime}, E^{\prime \prime}$. Endoderm (en) is outlined by dotted lines. Arrows in $C^{\prime}$ and $E-E^{\prime \prime}$ indicate endothelial cells. (D, $\left.D^{\prime}, F, F^{\prime}\right)$ Neural crest (GFP ${ }^{+}$, blue), Fn1 (red), Pecam1 (green). Fn1 protein is downregulated in $\mathrm{Fn}^{\text {flox/-}}$; Cre ${ }^{+}$mutants. The native GFP fluorescence was extinguished by boiling sections in $10 \mathrm{mM}$ citric acid (see supplementary Materials and Methods). See also Fig. S1. Scale bars: $100 \mu \mathrm{m}$.

in the NC cells surrounding the PAA endothelium is limited to the NC cells expressing Fn1.

In order to further understand the mechanisms by which Fn1 regulates activation of Notch and the differentiation of NC cells into VSMCs, we sought to identify receptors on NC cells that could transduce Fn1 signaling. Integrins are a major class of ECM receptors that connect the ECM with the actin cytoskeleton and transduce ECM signals into cells (Assoian and Schwartz, 2001; Giancotti and Tarone, 2003; Hynes, 2002; Schwartz and Assoian, 2001). Integrins are heterodimers comprising $\alpha$ - and $\beta$-subunits encoded by different genes; 18 genes encoding $\alpha$-chains and 8 genes encoding $\beta$-chains give rise to 24 distinct integrin heterodimers with distinct and overlapping specificities for ECM ligands (Hynes, 2012). Here, we show that enrichment of Fn1 around the PAA endothelium facilitates Notch activation and imparts the spatial specificity to Notch signaling by signaling through integrin $\alpha 5 \beta 1$. Our studies highlight the indispensable role of localized sources of Fn1 in cardiovascular development, and suggest that specific, spatiotemporal expression patterns of ECM proteins are important for regulating distinct morphogenetic programs.

\section{RESULTS}

Ablation of Fn1 in the NC results in cardiovascular abnormalities and perinatal lethality

Fn1 mRNA becomes detectable in the cardiac NC at about the 8th-10th somite stage of mouse development, and its expression is maintained in the dorsal neural tube at least until the 23rd somite stage (Mittal et al., 2010). Studies using Fnl flox/flox mice, a strain generated 14 years ago, show that the Fn1 protein is downregulated within $24 \mathrm{~h}$ of Cre expression (Sakai et al., 2001).
However, $24 \mathrm{~h}$ is a significant fraction of the 19 day gestation period. Thus, to avoid potential problems with the perdurance of Fn1 mRNA or protein after Cre-mediated recombination, we chose mouse lines in which Cre expression in the cardiac NC occurred early enough to ablate Fn1 before Fn1 mRNA was synthesized. Hence, we chose the transgenic P3Pro-Cre line and the knock-in Tfap $2 a^{I R E S C r e}$ strain for our experiments (Li et al., 2000; Macatee et al., 2003). In these strains, Cre expression in the cardiac NC is already evident by the 5 th-somite stage, which is $\sim 6 \mathrm{~h}$ prior to the onset of Fn1 mRNA expression in that region (Mittal et al., 2010; Stottmann and Klingensmith, 2011). To conditionally ablate Fn1 in the $\mathrm{NC}$ and its derivatives, we mated $F n l^{\text {flox flox }}$ animals harboring either the lacZ (R26R/R26R) or GFP (ROSA ${ }^{\mathrm{mTmG}}$ ) reporters in a homozygous state with $\mathrm{FnI}^{+/-}$; P3Pro-Cre ${ }^{+}$or $\mathrm{FnI}^{+/-}$; Tfap $2 a^{\text {IRESCre/+}}$ mice (Muzumdar et al., 2007; Soriano, 1999). The inclusion of reporters allowed the identification and tracking of NC descendants in control and mutant embryos. The relevant domains of Cre expression in these strains are schematically shown in Fig. S1A-B'. The use of P3Pro-Cre and Tfap $2 a^{\text {IRESCre }}$ strains resulted in efficient downregulation of $\mathrm{FnI}$ mRNA (compare Fig. 1C-C" with 1E-E") and protein (compare Fig. 1D, $\mathrm{D}^{\prime}$ with $1 \mathrm{~F}, \mathrm{~F}^{\prime}$ ) from the cardiac NC. In these and all other assays presented in this work, $\mathrm{NC}$ cells were identified by expression of GFP due to the presence of the ROSA ${ }^{m T m G}$ reporter allele (Muzumdar et al., 2007). For these and all other experiments involving immunofluorescence, the native GFP and tdTomato fluorescence was extinguished, as described in the Materials and Methods. Fn1 protein remaining around the pharyngeal blood vessels in the mutants (Fig. 1F, $\mathrm{F}^{\prime}$ ) is synthesized by the endothelium (arrows in Fig. 1E-E"). 
Cardiovascular phenotypes of the Fn $1^{\text {flox/- }}$; P3Pro-Cre ${ }^{+}$and Fn $1^{\text {flox/-}}$; Tfap $2 a^{\text {IRESCre }^{+}}$mutant embryos were comparable (Fig. 2, Fig. S2A-F and Tables S1 and S2). These mutants rarely survive the neonatal period (552 progeny were genotyped, Table S1) and exhibit a plethora of cardiovascular defects (Table S2). We also used the original Wnt1-Crel strain to complement our experiments (Jiang et al., 2000), but we observed only one incidence of RERSA among 42 Fn $^{\text {flox } /-}$; Wnt1-Cre1 embryos. Use of the new Wnt1-Cre2 strain, which was constructed to avoid the drawbacks of the Wnt1-Crel strain (Lewis et al., 2013), resulted in cardiovascular defects in 4 of 8 Fn $^{\text {flox } /-}$; Wnt1-Cre2 mutants (Fig. S2G-L' and Table S2). One of these mutants had both RERSA and IAA-B. The difference in the incidence of AAA defects between Fn $1^{\text {flox/- }}$; Wnt1-Crel and Fn $1^{\text {flox } /-}$; Wnt1-Cre2 mutants is significant, $P=0.0001$ (two-tailed Fisher exact test). The $\mathrm{NC}$ is the common domain of Cre expression among the Tfap $2 a^{\text {IRESCre }}$, P3Pro-Cre and Wnt1-Cre2 strains (Fig. $\mathrm{S}_{1} \mathrm{~A}^{\prime}, \mathrm{B}^{\prime}, \mathrm{C}^{\prime}$ ), indicating that the ablation of $F n 1$ in the NC caused the observed phenotypes. Since the Wnt1-Cre2 strain became available only recently, the majority of data in this paper were generated using the Tfap $2 a^{I R E S C r e}$ and P3Pro-Cre strains. The phenotypes of mutants generated using these strains were similar; Therefore for clarity, we will designate $F n 1^{\text {flox/ }-}$; Tfap $2 a^{I R E S C r e /+}$ and Fn1 flox/- ; P3Pro-Cre embryos as Fn $1^{\text {flox/- }}$; $\mathrm{Cre}^{+}$mutants and their $\mathrm{Cre}^{+}$littermate controls, as $\mathrm{FnI}^{\text {flox } /+} ; \mathrm{Cre}^{+}$, in the main text.

The most common malformations in $\mathrm{FnI}^{\text {flox/-}}$; $\mathrm{Cre}^{+}$mutants were: (1) aberrant patterning of the aortic arch arteries (compare Fig. 2A,B with D,E; see Fig. S2). The incidence of AAA defects varied from $57 \%$ to $82 \%$ among the three strains assayed (Table S2); (2) formation of the intracardiac cartilage, similar to that described in Gao et al. (2010) occurred at $89-100 \%$ penetrance (Chen et al., 2015); and (3) the membranous ventricular septal defect (VSD; curved arrow in Fig. 2F): 29-42\% penetrance (Table S2). Cardiac $\mathrm{NC}$ contributes mesenchymal cells to the thymus, regulating morphogenesis of this organ (Bockman and Kirby, 1984); consistent with that, we found that $44 \%$ of mutant embryos had mild defects in thymus development (Chen et al., 2015). Taken together, these phenotypes are characteristic of many other mouse mutants with defective development or function of the cardiac NC
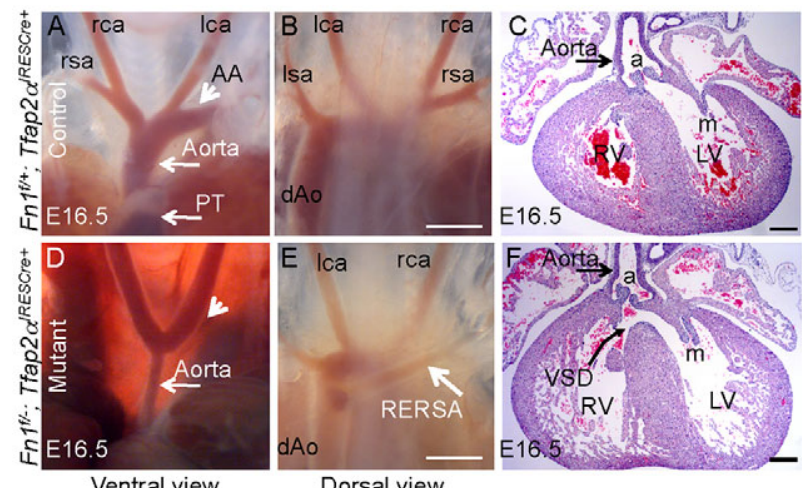

Ventral view

Dorsal view

Fig. 2. $F n 1^{\text {floxl- }} ;$ Tfap2a $a^{I R E S C r e /+}$ mutants develop defects in AAA morphogenesis and ventricular septation. (A-C) Controls; (D-F) mutants. Small arrow in D indicates missing aortic arch (AA) in the mutants. Arrow in $E$ indicates RERSA (retroesophageal right subclavian artery), originating from the dorsal aorta (dAo). (C,F) Coronal sections through the equivalent levels of control $(C)$ and mutant $(F)$ hearts show the presence of the ventricular septal defect (VSD, curved arrow in F) in the mutants. AA, aortic arch; dAo, dorsal aorta; Ica, rca, left and right carotid arteries; Isa, rsa, left and right subclavian arteries; PT, pulmonary trunk; a, aortic valve; $m$, mitral valve; LV and RV, left and right ventricles. See also Fig. S2. Scale bars: $200 \mu \mathrm{m}$.
(Hutson and Kirby, 2007). None of these malformations were observed in 267 control embryos examined at E14.5, E16.5 or E18.5.

$\mathrm{NC}$ cells arising at the same level of the neural tube as the cardiac $\mathrm{NC}$, also contribute to the cardiac, enteric, sympathetic, parasympathetic and sensory nervous systems (Le Douarin and Kalcheim, 1999). However, with the exception of the palatal shelves, all other NC-derived lineages, such as dorsal root ganglia ( $n=4 / 4$ mutants), enteric nervous system ( $n=14 / 15$ mutants) and parasympathetic innervation of the heart and the diaphragm $(n=6 / 6$ mutants) developed grossly normally in FnI ${ }^{\text {flox/-}}$; $\mathrm{Cre}^{+}$mutants (Fig. S2M-T). Cleft palates were found in all FnI flox/Tfap $2 a^{\text {IRESCre/+ }}$ mutants and in 4 out of $5 \mathrm{FnI}^{\text {flox/- }}$; Wnt1-Cre 2 mutants (Fig. S2U-X). These findings indicate that NC-derived Fn1 is specifically required for the development of a narrow subset of the cranial NC.

\section{NC-derived Fn1 is required for the differentiation of NC cells into vascular smooth muscle cells}

AAA defects in $F n 1^{f l o x /}{ }^{-} ; \mathrm{Cr}^{+}$mutants generated using the TFAp2alRESCre, P3Pro-Cre or Wnt1-Cre2 strains included RERSA, interrupted aortic arch type B (IAA-B), hypoplastic aortic arch and the right-sided aortic arch (Fig. 2, Fig. S2, Table S2); in 6 of $43 \mathrm{FnI}^{\text {flox/-}}$; $\mathrm{Cre}^{+}$mutants, RERSA and IAA-B occurred concurrently. These defects are specific to abnormal development of the 4th pair of PAAs (Stoller and Epstein, 2005) and could be due to either defective PAA formation or defective remodeling of the well-formed PAAs into the AAAs (Conway et al., 2003). Injection of black India ink into the hearts of control and mutant embryos isolated at E10.5 showed that the three pairs of PAAs formed normally $(n=3)$ (Chen et al., 2015). Similarly, examination of histological sections in $n>10$ mutants and controls 1 day later, at E11.5, indicated that all of the PAAs were well formed in the mutants (e.g. compare Fig. 3A,E). Therefore, the AAA defects observed in our mutants at E14.5-E16.5 were due to pathological regression of the initially well-formed 4th pair of PAAs. These phenotypes are analogous to other mutants with defective development of the cardiac NC (Hutson and Kirby, 2007). In such mutants the originally well-formed 4th pair of PAAs regressed because of either (a) insufficiency in cardiac NC cell population or (b) defective differentiation of the cardiac $\mathrm{NC}$ into VSMCs (Conway et al., 2003; Stoller and Epstein, 2005).

Consistent with our previous studies showing that Fn1 was not required for NC migration in global Fn1-null mutants (Mittal et al., 2010), the deletion of Fn1 in NC cells did not impair NC migration (compare Fig. S3A-B" with C-D"). However, unlike in the global Fn1-null embryos, Fn1 synthesized by the NC was not required for $\mathrm{NC}$ cell survival (Fig. S3B"', $\mathrm{D}^{\prime \prime \prime}$ ), suggesting that other cellular sources of Fn1 regulate NC survival.

At E11.5, population densities of NC-derived cells in the control and mutant pharyngeal arches were comparable (compare Fig. 3A,E, blue; quantified in Table S3). However, the coverage of the 4th pair of PAAs with VSMCs was defective in 17 of $25 \mathrm{FnI}^{\text {flox/-}}$; $\mathrm{Cre}^{+}$ mutants (compare Fig. 3A-D with E-H; quantified in Fig. S4). Four VSMC markers were assayed, $\alpha$ SMA (Acta2), SM22 $\alpha$ (Tagln1), calponin (Cnnl) and smooth muscle myosin heavy chain 11 (Myh11), and we found coordinated downregulation of all of these markers in cardiac NC-derived cells in Fn1 $\mathrm{flox}^{-}$; $\mathrm{Cr}^{+}$mutants (Fig. 3E-H). As expected, the development of VSMCs around the dorsal aorta (DA) was not affected in our mutants (Fig. 3A,E) because these VSMCs are derived from the mesodermal progenitors and not from the NC.

Vascular expression of the ECM protein fibulin-1, which is required for the development of the cardiac $\mathrm{NC}$ and $\mathrm{AAA}$ 

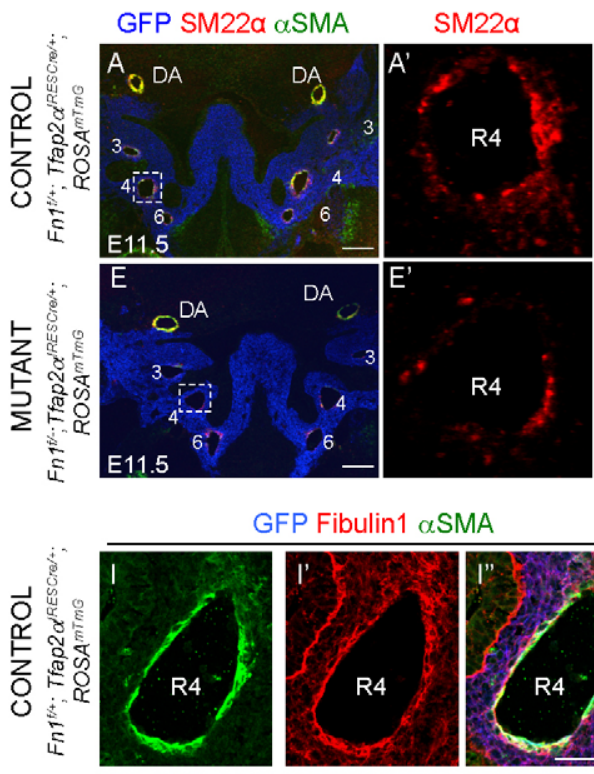

GFP Fibulin1 $\alpha$ SMA
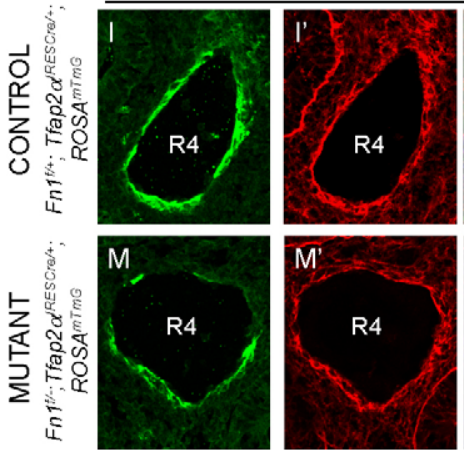
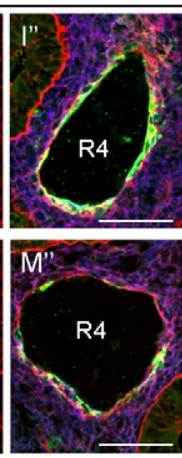

$\alpha$ SMA
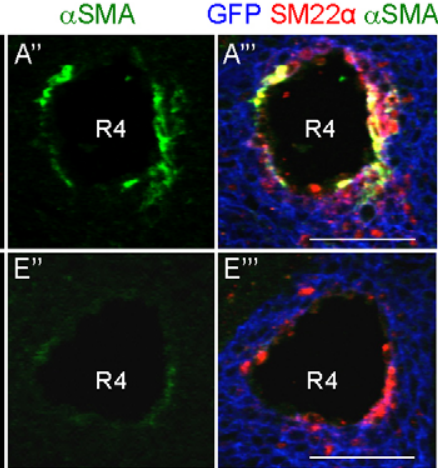

GFP Laminin $\gamma 1 \alpha$ SMA
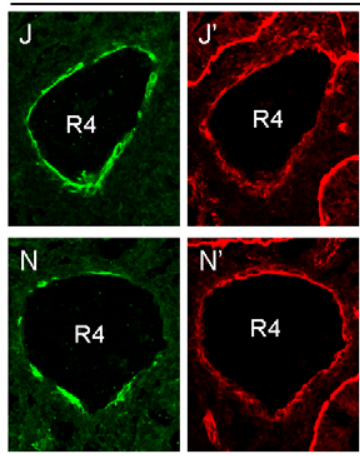
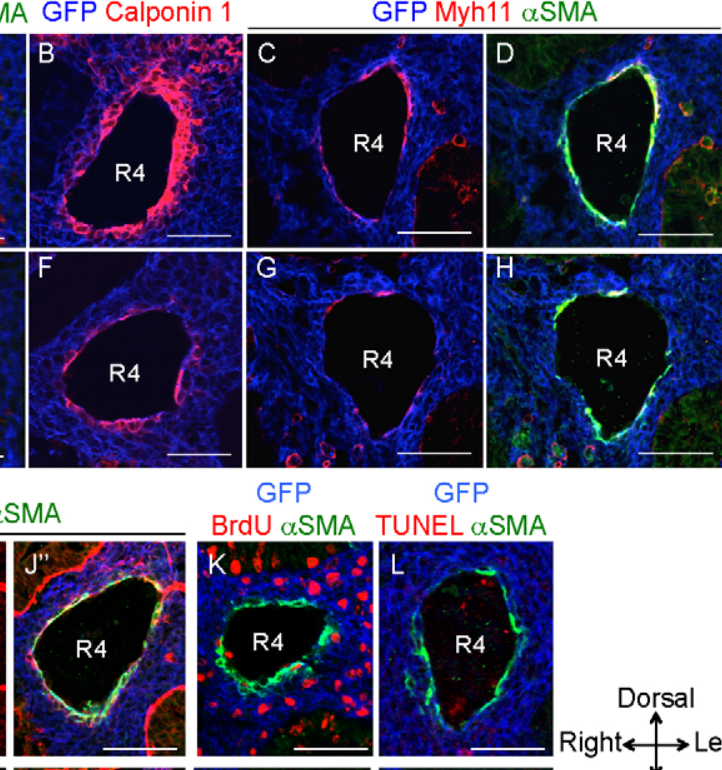

GFP

GFP

BrdU $\alpha$ SMA TUNEL $\alpha$ SMA
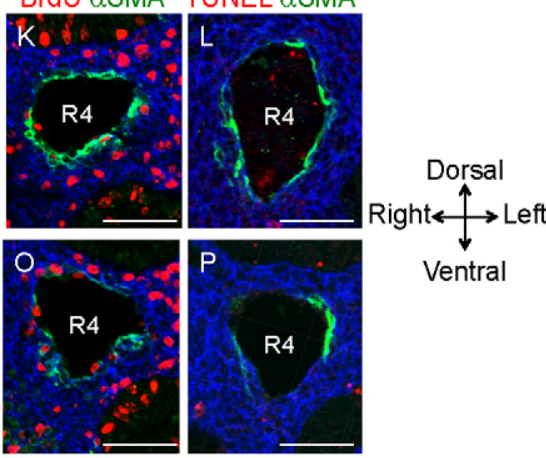

Fig. 3. NC-derived Fn1 is required for the differentiation of NC cells into VSMCs in vivo. Coronal sections of control (A-D,I-L) and mutant (E-H,M-P) E11.5 embryos. Analyses of VSMC marker expression in control (A-D) and mutant (E-H) embryos show deficient expression of VSMC markers in NC cells (GFP ${ }^{+}$, blue) surrounding the PAAs in the mutants. Boxed areas in $A$ and $E$ are expanded in $A^{\prime}-A^{\prime \prime \prime}$ and $E^{\prime}$ - $E^{\prime \prime \prime}$. The expression of $E C M$ proteins fibulin-1 and laminin $\gamma 1$ are comparable around the PAAs in controls $\left(\mathrm{I}-\mathrm{J}^{\prime \prime}\right)$ and mutants $\left(\mathrm{M}-\mathrm{N}^{\prime \prime}\right)$. Proliferation $(\mathrm{K}, \mathrm{O})$ and survival $(\mathrm{L}, \mathrm{P})$ of NC cells around the PAAs is not affected in the mutants. Axes are marked. Pharyngeal arch arteries are numbered. DA, dorsal aorta; R4, right fourth PAA. Native GFP fluorescence was extinguished by boiling sections in $10 \mathrm{mM}$ citric acid (see supplementary Materials and Methods). For additional NC analyses at E9.5, see Fig. S3. For quantification of VSMC coverage at E11.5, see Fig. S4. Scale bars: $100 \mu \mathrm{m}$ in A,E; $50 \mu \mathrm{m}$ in all other panels.

morphogenesis (Cooley et al., 2008) was not affected in our mutants (Fig. 3I-I",M-M") and neither was the expression of laminin $\gamma-1$ (Fig. 3J-J",N-N"), which is a component of vascular basement membranes (Yurchenco, 2011). We also did not observe differences in activation of SMAD2/3 and SMAD1/5/8 between controls and mutants (Fig. S6). Proliferation and survival of NC cells surrounding the PAAs (Fig. 3K,L,O,P) were also not affected in the mutants, Table S3. Taken together, our data indicate that Fn1 synthesized by NC-derived cells is required for the differentiation of NC cells into VSMCs. Furthermore, these data suggest that the mechanisms of Fn1mediated NC-to-VSCM differentiation do not involve the regulation of ECM deposition or signaling by the TGF $\beta$ family of proteins.

Remodeling of the PAAs observed in wild-type embryos involves stage-dependent, stereotypical regression of the right 6th PAA and partial regression of the right 4th PAA, which gives rise to a small segment of the right subclavian artery (Hutson and Kirby, 2007); the left 4th PAA persists and gives rise to the aortic arch. The left 6th PAA persists during fetal development and gives rise to the ductus arteriosus (Hutson and Kirby, 2007). By contrast, in animal models with cardiac NC deficiency, PAA regression occurs at random (Leatherbury et al., 1990; Nishibatake et al., 1987; Olaopa et al., 2011; Porras and Brown, 2008). This leads to variable aberrations in the final configuration of the AAAs, similar to the phenotypes observed in our mutants (Table S2, Fig. 2 and Fig. S2). Consistent with these findings, we observed that NC differentiation into VSMCs was affected on the left, right or both sides of the mutant embryos (Fig. S4). VSMC deficiency around the left 4th PAA is expected to result in the regression of this PAA, and give rise to the interrupted aortic arch (IAA-B). VSMC deficiency around the right 4th PAA is expected to result in the regression of the right 4th PAA and to give rise to RERSA, and we observed IAA-B, RERSA or both IAA-B and RERSA in $\mathrm{FnI}^{\text {flox/-}}$; $\mathrm{Cre}^{+}$mutants (Fig. 2, Fig. S2 and Table S2). Taken together, our studies indicate that defective morphogenesis of AAAs in $\mathrm{Fn}_{n}{ }^{\text {flox/-}}{ }^{-}$; $\mathrm{Cre}^{+}$embryos result from the reduced differentiation of cardiac $\mathrm{NC}$ cells into VSMCs and that the NC-derived source of Fn1 plays a fundamental role in regulating cardiovascular morphogenesis.

\section{NC-synthesized Fn1 regulates the differentiation of NC cells into smooth muscle cells in an NC cell-autonomous manner}

On their way to pharyngeal arches, NC cells migrate through the cranial mesoderm that expresses Fnl (Mittal et al., 2010; Peters and Hynes, 1996). NC cells directly adjacent to the PAA endothelium within the pharyngeal arches are exposed to endothelial Fn1 (Fig. 1C-D $\mathrm{D}^{\prime}, \mathrm{E}-\mathrm{F}^{\prime}$ ). Nevertheless, these paracrine sources of Fn1 are not sufficient to support the differentiation of NC cells into VSMCs and AAA morphogenesis (Fig. 2A,B,D,E, Fig. S2A-K' and Fig. 3). Taken together, these data suggest that NC-derived Fn1 mediates differentiation of $\mathrm{NC}$ cells into VSMCs in NC cell-autonomous manner. In order to test this hypothesis directly, we isolated NC cells from one of two sources: from a fragment of the neural tube (NT) located between the otic pit and the 4th somite and corresponding with the origin of the cardiac NC (Fig. 4A,B) or from the pharyngeal arches 3-6 containing cardiac $\mathrm{NC}$ cells, including those destined to give rise to PAA VSMCs (Fig. 4C,D). In these assays, NC cells were identified by the expression of GFP due 

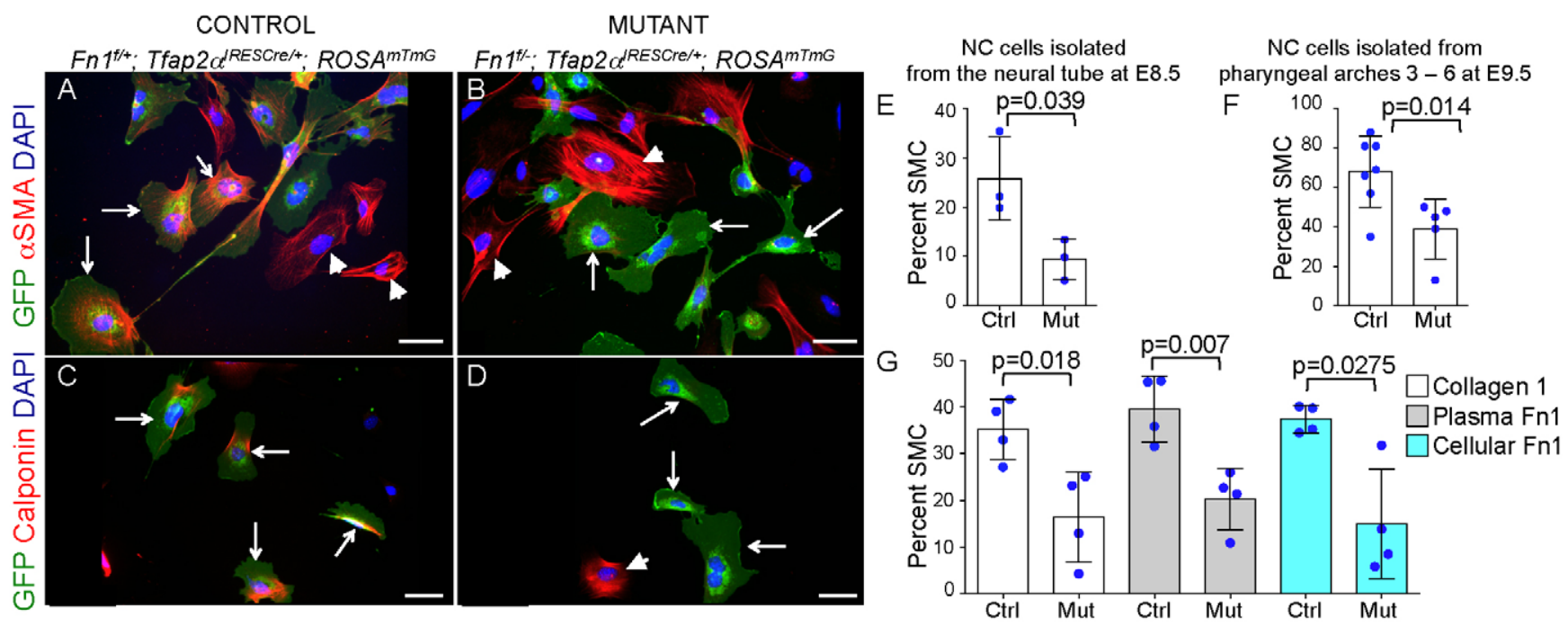

Fig. 4. Fn1 synthesized by the NC regulates the differentiation of NC cells into smooth muscle cells in vitro. NC cells were cultured under smooth

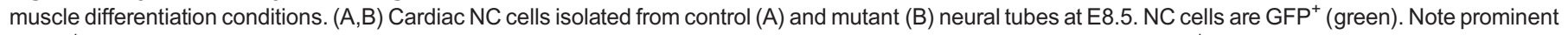

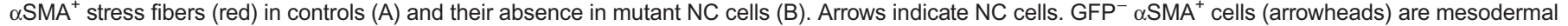
cells co-isolated with the NC. NC cells from control (C) and from mutant embryos (D) isolated from the pharyngeal arches 3-6 at E9.5. Arrows indicate NC cells (green), arrowheads indicate mesodermal cells. Calponin (red) is expressed by control but not by mutant NC-derived cells. (E) Analyses of SMC

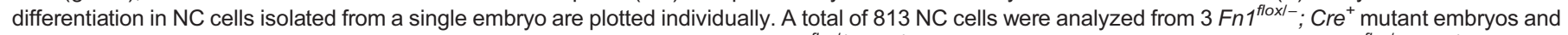

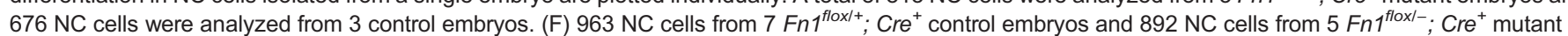

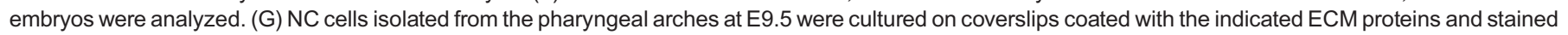
to detect $\alpha$ SMA. Each data point is collected from one cultured embryo. Culture of Fn1-deficient NC cells on plasma or cellular Fn1 did not rescue smooth

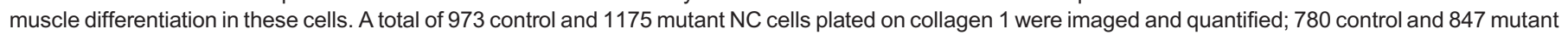
NC cells plated on pFn1 were imaged and quantified, and 843 control and 1062 mutant NC cells plated on cFn1 were imaged and quantified. Statistics were performed using two-tailed, unpaired Student's $t$-test with Welch's correction for unequal s.d. Means $\pm s$.d. are shown. Scale bars: $50 \mu \mathrm{m}$.

to the presence of the $R O S A^{m T m G}$ reporter allele (Muzumdar et al., 2007). Expression of $\alpha \mathrm{SMA}$ (Acta2) or calponin (Cnn1) was used as a readout of smooth muscle differentiation. These experiments demonstrated that Fn1-deficient NC cells were impaired in their differentiation into smooth muscle cells in vitro (Fig. 4A-D, quantified in Fig. 4E,F).

Fn1 protein is highly evolutionarily conserved among species (Hynes, 2012) and isolated Fn1 proteins from different species are used interchangeably in vitro. In all of the in vitro experiments described above, $\mathrm{NC}$ cells isolated from control and mutant embryos were cultured in the presence of $10 \%$ fetal bovine serum and contained plasma Fn1, one of the most abundant serum proteins. However, the presence of plasma Fn1 was not sufficient to restore the full smooth muscle differentiation potential to Fn1-deficient NC cells (Fig. 4E,F). It is important to note that the differentiation of control NC cells into smooth muscle cells in the presence of Fn1-depleted FBS was minimal in both control and mutant NC cultures (data not shown). This latter observation is consistent with the studies described by Costa-Silva et al. (2009), which suggested that plasma Fn1 potentiates the differentiation of NC cells into VSMCs.

Plasma Fn1 is different from Fn1 synthesized by NC cells, since virtually all embryonic forms of Fn1 include the EIIIA and EIIIB alternatively spliced exons at mid-gestation, whereas plasma Fn1 is devoid of both (Astrof et al., 2007; Hynes, 1990; Peters and Hynes, 1996). Our previous genetic studies indicated that EIIIA $^{-}$EIIIB $^{-}$forms of Fn1 were insufficient to support normal embryonic development, and that deletion of both the EIIIA and EIIIB exons from $F n 1$ led to NC-related cardiovascular defects, despite the fact that EIIIA $^{-}$EIIIB $^{-}$Fn1 in these mutants was synthesized at levels similar to those of wild-type Fn1 in control embryos (Astrof et al., 2007). In addition, soluble plasma Fn1 in culture medium could be in a different conformation than the solid-state Fn1 present in ECM or adsorbed to tissue culture plates. To test whether Fn1-coated glass slides could rescue smooth muscle differentiation in Fn1-deficient NC cells, we plated control and mutant $\mathrm{NC}$ cells on glass coverslips coated with collagen 1 , human plasma Fn1 or human cellular Fn1 containing EIIIA and EIIIB splice variants (Fig. 4G). However, consistent with our in vivo data, Fn1 provided in trans did not rescue smooth muscle differentiation defects in Fn1-deficient NC cells (Fig. 4G). These findings indicate that $\mathrm{NC}$-derived $\mathrm{Fn} 1$ regulates smooth muscle differentiation in a $\mathrm{NC}$ cell-autonomous manner.

\section{NC-synthesized Fn1 regulates Notch signaling}

Several pathways are known to regulate the differentiation of NCderived cells into VSMCs around PAAs 3-6 (Arnold et al., 2013; High and Epstein, 2008; Kaartinen et al., 2004; Li et al., 2005; Oh et al., 2005; Vallejo-Illarramendi et al., 2009). Among these, the role of Notch signaling has been particularly well studied (High and Epstein, 2008; High et al., 2008, 2007; Manderfield et al., 2015, 2012). Active Notch is an upstream regulator of NC differentiation into VSMCs (High et al., 2007; Manderfield et al., 2012). Prior experiments indicated that Notch signal is transduced from PAA endothelial cells to the adjacent NC-derived mesenchyme, leading to the expression of Notch target genes Jagged 1, Heyl and Hey 2 in the NC. Notch signal is then relayed from one NC cell layer to the next as a result of induction of Jagged 1 in these cells - a process termed lateral induction (Eddison et al., 2000; Manderfield et al., 2012; Ross and Kadesch, 2004). In this process, Jagged1 expressed by the proximal NC cells binds Notch expressed in next NC cell layer, which activates Notch signaling. The relay of Notch signal through the consecutive NC cell layers leads to smooth muscle gene expression and VSMC differentiation in those NC cells that are marked by the activated Notch (Boucher et al., 2011; Doi et al., 
2006; High et al., 2008; Manderfield et al., 2012; Noseda et al., 2006; Tang et al., 2008). However, the Notch signal is not relayed through the indefinite number of NC cell layers, but is confined to a few NC cell layers nearest the PAA endothelium (High et al., 2007). How this relay is terminated is unknown (Manderfield et al., 2012).

We noticed that the expression domains of Fn1 and Jagged1 proteins overlapped and diminished coordinately with increasing distance from the PAA vessel lumen (Fig. 5A-E). The expression of $F n 1$ mRNA is also enriched in NC layers proximal to the PAA endothelium (Fig. 1C-C") and this expression pattern corresponds with the mRNA expression of other downstream targets of Notch Heyl and Hey2 (Fig. 5J,K and Fig. 6I-J'). These data show that Notch signaling around the PAA endothelium is mainly active within the NC cell layers that express $F n 1$.

These observations prompted us to ask whether Fn1 regulated Notch signaling in the NC. To answer this question, we investigated the expression of Notch transcriptional targets Jagged1, Heyl and $\mathrm{Hey} 2$, as well as the expression of the active form of Notch - the
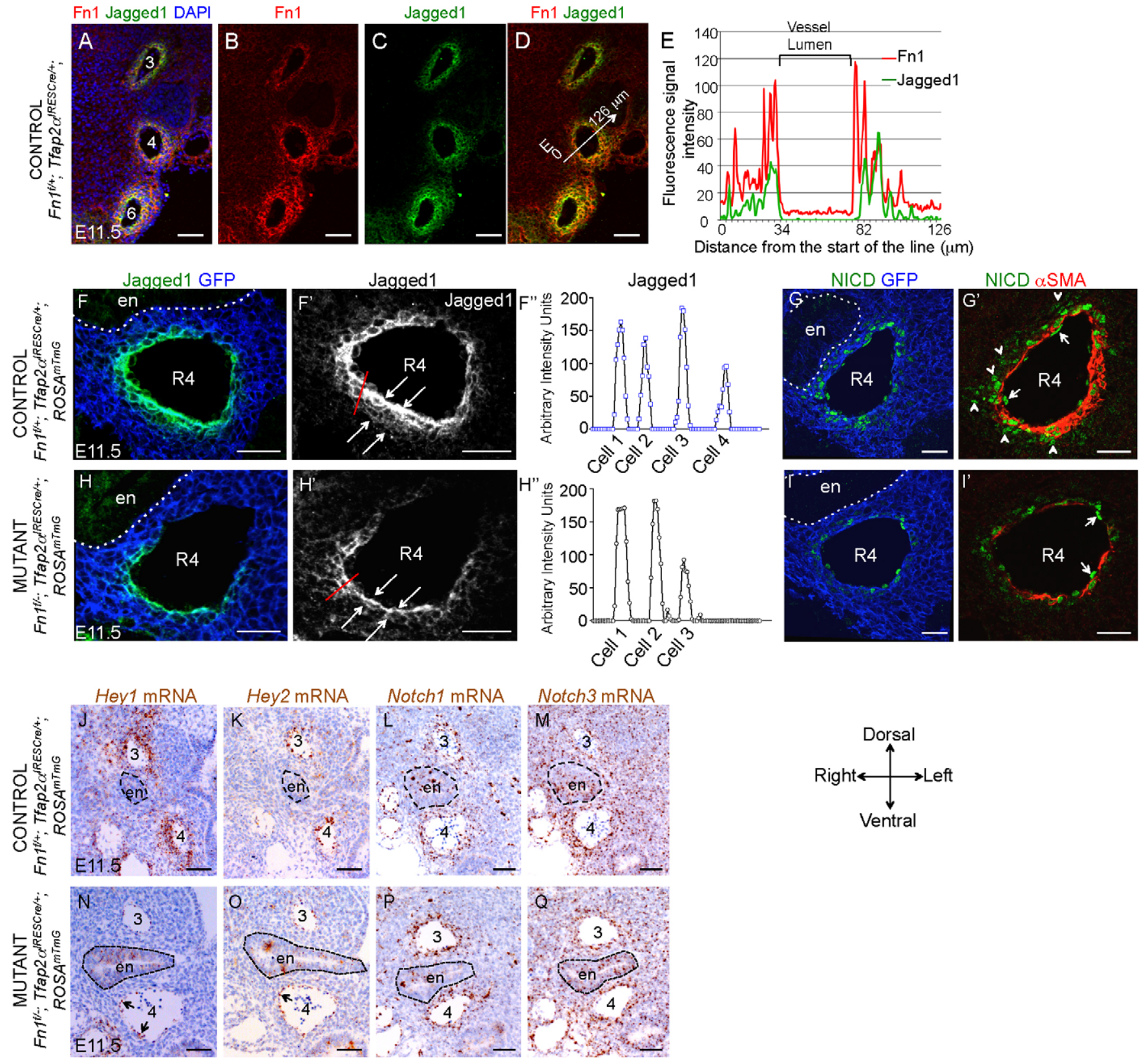

Fig. 5. Fn1 regulates Notch signaling in NC cells surrounding the PAAs. (A-E) The Fn1 (red) and Jagged 1 (green) proteins are co-enriched in NC cells surrounding the PAA endothelium. Fluorescence intensity along the line in D is plotted in E. (A-G', J-M) Controls; (H-I',N-Q) mutants. Jagged1 fluorescence (green) $(F, H)$ is shown in a separate channel $\left(F^{\prime}, H^{\prime}\right)$. White arrows indicate the extent of Jagged1 expression around the PAA. $\left(F^{\prime \prime}, H^{\prime \prime}\right)$ Jagged1 fluorescence measured along the red lines is shown in $\mathrm{F}^{\prime}$ and $\mathrm{H}^{\prime}$ using the plot profile function in ImageJ. Each peak of fluorescence occurs at cell borders. In control (F-F"), Jagged1 fluorescence is detectable over four cell borders; in the mutant $\left(\mathrm{H}-\mathrm{H}^{\prime \prime}\right)$ Jagged1 expression wanes at the third cell border. The first cell border occurs at the endothelial-NC interface. (G, $\left.G^{\prime}, I, I^{\prime}\right)$ NICD in the nuclei of NC cells surrounding the right 4th PAA in control (G, $G^{\prime}$, arrowheads). NICD expression in the mutant is mainly confined to the PAA lumen ( $\mathrm{I}^{\prime}$, arrows). (J-Q) In situ hybridization. In controls (J-K), Hey1 and Hey2 are expressed in the PAA endothelium and in adjacent NC cells. In the mutants, Hey1 and Hey2 expression is confined mostly to the endothelium (arrows) (N,O). The expression patterns of Notch1 and Notch3 are similar in controls $(L, M)$ and in the mutants $(P, Q)$. Endoderm (en) is outlined by the dotted lines. Axes are shown. Scale bars: $50 \mu \mathrm{m}$ in J-Q; $30 \mu \mathrm{m}$ in all other panels. 


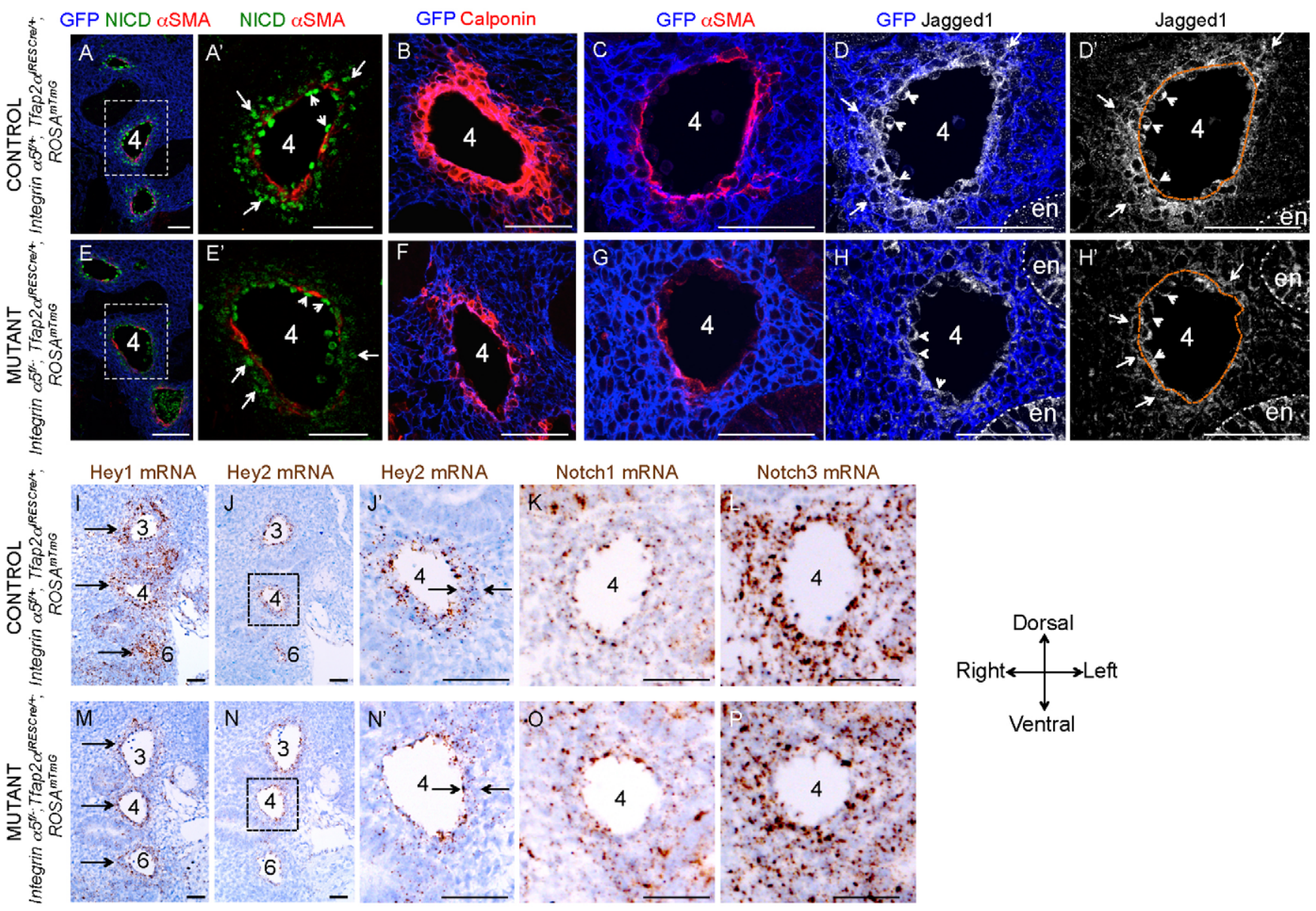

Fig. 6. Integrin $\alpha 5 \beta 1$ regulates Notch signaling and VSMC differentiation in NC-derived cells. Coronal sections through $E 11.5$ Itga $5^{f l o x /+} ;$ Tfap2a $a^{I R E S C r e /+}$ control (A-D',I-L) and Itga $5^{\text {flox/- }}$; Tfap2a ${ }^{\text {IRESCre/+ }}$ mutant embryos $\left(\mathrm{E}-\mathrm{H}^{\prime}, \mathrm{M}-\mathrm{P}\right)$. NICD (green) localizes to nuclei within multiple layers of NC cells (GFP ${ }^{+}$, blue, arrows) in controls $\left(A, A^{\prime}\right)$ but in the mutants $\left(E, E^{\prime}\right), N I C D$ is mainly confined to the endothelium, arrowheads. Arrows indicate $N I C D^{+} N C$ cells. $\left(A^{\prime}, E^{\prime}\right) \alpha S M A$ and $(B, F)$ calponin are downregulated in the mutants. (C-D',G-H') Expression of $\alpha$ SMA and Jagged1 are coordinately downregulated in the mutants $\left(G-H^{\prime}\right)$. $\left(C-D^{\prime}\right)$ Views of the same control section. (G-H') Views of the same mutant section. Arrows in $D, D^{\prime}, H^{\prime}$ indicate NC cells expressing Jagged1. Arrowheads in $D, D^{\prime}, H, H^{\prime}$ indicate endothelial cells expressing Jagged1. Endoderm (en) is outlined by the dotted white lines in $D, D^{\prime}$ and $H, H^{\prime}$. Note that Jagged1 staining in the mutants is mainly confined to the endothelial-NC cell border (dotted brown line). (I-J',M-N') Hey1 and Hey2 mRNAs are downregulated in the mutants $\left(\mathrm{M}-\mathrm{N}^{\prime}\right)$. Compare area between the arrows in $\mathrm{J}^{\prime}$ and $\mathrm{N}^{\prime}$. The outlined boxes in $\mathrm{J}$ and $\mathrm{N}$ are expanded in $\mathrm{J}^{\prime}, \mathrm{N}^{\prime}$. (K,L,O,P) Expression of Notch1 and Notch3 in NC-derived cells surrounding the PAAs were not affected in the mutants. K,L are serial sections to C-D'. O,P are serial sections to G-H'. Scale bars: $50 \mu m$.

Notch intracellular domain (NICD) - in NC cells surrounding the 4th pair of PAAs in $\mathrm{FnI}^{\text {flox/-}}{ }^{-} \mathrm{Cre}^{+}$mutants and controls at E11.5. For these analyses, we chose those $\mathrm{FnI}^{\text {flox/-}}{ }^{-}$; $\mathrm{Cre}^{+}$mutants in which $\alpha$ SMA expression in the NC around the PAAs was downregulated and used their littermate controls for comparisons (Fig. 5F-Q). Our experiments indicated that the expression of Jaggedl was downregulated in 5 of $6 \mathrm{Fn} \mathrm{flox}^{\mathrm{flo}}$; $\mathrm{Cre}^{+}$mutants with defective VSMC differentiation (compare Fig. 5F, $\mathrm{F}^{\prime}$ with $\mathrm{H}, \mathrm{H}^{\prime}$ ). Moreover, compared with the mutants, expression of Jagged1 in controls was maintained over a wider number of $\mathrm{NC}$ cell layers surrounding the PAAs (compare Jagged1 intensity profiles in Fig. 5F", $\mathrm{H}^{\prime \prime}$, each peak is Jagged1 fluorescence at consecutive cell borders). Similarly, NICD was expressed in multiple NC cell layers surrounding the 4th PAA in controls (Fig. 5G, $\mathrm{G}^{\prime}$, arrowheads). By contrast, the expression of NICD in the NC was downregulated in all 3 of 3 examined $\mathrm{FnI}^{\text {flox/-}}$; $\mathrm{Cr} e^{+}$mutants (Fig. 5G, $\mathrm{G}^{\prime}, \mathrm{I}, \mathrm{I}^{\prime}$ ) and was mainly confined to the endothelial cell layer (Fig. 5I', arrows). Heyl and Hey 2 mRNAs were downregulated in 4 of 4 examined Fnlflox/-; $\mathrm{Cre}^{+}$mutants (Fig. 5J,K,N,O).

Antibodies against the activated form of Notch (NICD) recognize cytoplasmic domains of Notch1 and Notch3. To test whether Fn1 regulated Notch signaling through expression of Notch1 and Notch3, we performed in situ hybridization to detect the expression of these receptors in the mutants with downregulated expression of $\alpha \mathrm{SMA}$ and Jagged1. These experiments showed that Notch 1 and Notch 3 were expressed at similar levels in controls and Fn1 flox/- $; \mathrm{Cre}^{+}$mutants, $n=3 / 3$, (Fig. 5L,M,P,Q). These findings suggested that $\mathrm{Fn} 1$ regulates Notch signaling rather than the expression of Notch receptors.

Taken together, our studies demonstrated that NC-synthesized Fn1 regulates Notch signaling in NC cells around the PAAs, and showed that active Notch signal is confined to the region of NC cells enriched in Fn1 protein. These results are consistent with the idea that the enrichment of $F n 1$ mRNA and protein in the NC cell layers adjacent to the PAA endothelium imposes a spatial specificity to Notch signaling, and limits Notch signaling and NC-to-VSMC differentiation to this region.

Fn1 regulates activation of Notch and NC differentiation into VSMCs by signaling through integrin $\alpha 5 \beta 1$

If Fn1 regulates the differentiation of NC cells into VSMCs in a $\mathrm{NC}$ cell-autonomous manner, $\mathrm{NC}$ cells must express receptors that 
transduce Fn1 signals regulating Notch signaling and NC-to-VSMC differentiation. NC cells are known to express a number of Fn1 receptors, including $\alpha \mathrm{v}-, \alpha 4-$ and $\alpha 5$-containing integrin heterodimers (Grazioli et al., 2006; Haack and Hynes, 2001; Testaz et al., 1999). Integrin $\alpha 5 \beta 1$ is thought to be a major Fn1 signal transducer during early to mid-gestation (George et al., 1997, 1993; Mittal et al., 2013, 2010; Pulina et al., 2014, 2011; Takahashi et al., 2007; Yang et al., 1999, 1993). Therefore, we asked whether integrin $\alpha 5 \beta 1$ was required for activation of Notch and differentiation of NC-derived cells into VSMCs. Conditional deletion of integrin $\alpha 5$ in the $\mathrm{NC}$ using the same Cre-expressing strains as above resulted in defective differentiation of the cardiac $\mathrm{NC}$ cells into VSMCs in 11 of 20 integrin $\alpha 5$ mutants (Itga $5^{\text {flox/- }}$; $\mathrm{Cre}^{+}$), assayed either by expression of $\alpha \mathrm{SMA}$ or calponin (compare red signal in Fig. 6A-C with E-G), quantified in Fig. S5. To test whether Notch signaling in the $\mathrm{NC}$ was also dependent on integrin $\alpha 5$, we examined Notch activation in Itga $5^{\text {flox } /-} ; \mathrm{Cr}^{+}$mutants exhibiting defective VSMC differentiation. Similar to $F n 1^{\text {flox/- }}$; $\mathrm{Cre}^{+}$mutants, expression of NICD was limited to the immediate vicinity of the PAA endothelium in 4 of 4 Itga $5^{\text {flox } /-}$; $\mathrm{Cre}^{+}$mutants, whereas in controls, NICD was present in multiple NC cell layers (compare green signal in Fig. 6A, $\mathrm{A}^{\prime}$ with E, $\mathrm{E}^{\prime}$ ). As with $F n 1^{\text {flox } /-}$; $\mathrm{Cre}^{+}$mutants, we found that Jagged 1 expression was limited to the immediate vicinity of the PAA endothelium in 5 of 5 integrin Itga $5^{\text {flox }-}$; $\mathrm{Cre}^{+}$mutants (compare Fig. $6 \mathrm{D}, \mathrm{D}^{\prime}$ with $\mathrm{H}, \mathrm{H}^{\prime}$ ). Consistent with these findings, Heyl and Hey 2 mRNA was downregulated in 4 of 4 Itga $5^{\text {flox/- }} ; \mathrm{Cre}^{+}$mutants (compare Fig. 6I-J' with M-N'). Expression of Notch1 and Notch3 was not affected in Itga $5^{\text {flox } /-}$; $\mathrm{Cr}^{+}$mutants with defective expression of $\alpha$ SMA and Jagged1 (Fig. 6K,L,O,P). These findings indicated that expression of integrin $\alpha 5$ by NC cells is required for Notch signaling in the NC and differentiation of NC cells into VSMCs.

To test whether impaired Notch signaling was the cause of defective smooth muscle differentiation in integrin- $\alpha 5$-deficient NC cells, we asked whether activation of Notch in mutant NC cells would restore their ability to differentiate into VSMCs. NC cells isolated from Itga $5^{\text {flox/-}}$; $\mathrm{Cr}^{+}$mutants lack integrin $\alpha 5 \beta 1$ (compare Fig. 7A-A" with B-B") and exhibit defective smooth muscle differentiation, assayed by the expression of $\alpha \mathrm{SMA}$ or calponin (Fig. 7C,D, quantified in G, 'not infected' columns). However, activation of Notch signaling in integrin- $\alpha 5$-deficient NC cells by expression of the Notch1 intracellular domain N1ICD (Tang et al., 2008) - but not of control proteins - restored smooth muscle differentiation in these cells (Fig. 7E-G), indicating that integrin $\alpha 5$ regulates $\mathrm{NC}$ differentiation into VSMCs by activating Notch signaling.

Our findings are consistent with the model that NC-synthesized Fn1 regulates the activation of Notch and VSMC differentiation by signaling through integrin $\alpha 5 \beta 1$ expressed by the cardiac $\mathrm{NC}$. We hypothesize that as the PAAs grow in diameter between E10.5 and E11.5 stages of development, a morphogen secreted by the PAA endothelium induces high levels of Fn1 expression in NC cells adjacent to the PAA endothelium and that the region of Fn1 expression in the $\mathrm{NC}$ is determined by the diffusion/threshold levels of this morphogen (Fig. 7H). Alternatively, Fn1 transcription in the NC could be induced by mechanical tension arising due to the increasing hemodynamic shear stress on the endothelium in the growing PAAs (Bordeleau et al., 2015; Chiquet et al., 2003; Liu et al., 2000). Regardless of how Fn1 is induced, our studies support the hypothesis that enriched expression of Fnl in NC cells around the 4th pair of PAAs imposes a spatial specificity on Notch activation and VSMC differentiation in the $\mathrm{NC}$, and regulates the complex process of PAA remodeling.

\section{DISCUSSION \\ Role of Fn1 and integrin $\alpha 5$ in NC development and cardiovascular morphogenesis}

Our previous studies revealed that $F n 1$ mRNA and protein are expressed in non-uniform, dynamic patterns during embryogenesis (Mittal et al., 2010). The high evolutionary conservation of Fnl and the essential role of Fn1 in cardiovascular development suggested that enriched expression of Fn1 in specific embryonic regions is biologically significant. The studies described in this paper and in our earlier publication (Chen et al., 2015) reveal requisite, cell typespecific functions of $\mathrm{Fn} 1$ in embryogenesis and cardiovascular development.

We used three different strains of mice, the P3Pro-Cre and Wnt1Cre 2 transgenic lines and the Tfap $2 a^{\text {IRESCre }}$ knock-in mice to determine the role of Fn1 synthesized by the NC. These experiments demonstrated that specific expression of $\mathrm{Fn} 1$ in the $\mathrm{NC}$ is required for the development of the palate and the cardiovascular system. Furthermore, we showed that NC-synthesized Fn1 was specifically required for the asymmetrical remodeling of the PAAs into the AAAs by regulating Notch signaling and differentiation of NCderived cells into VSMCs.

Despite the presence of Fn1 at the interface between the PAA endothelium and NC cells in $\mathrm{Fn}^{\text {flox/-}}{ }^{\text {; }} \mathrm{Cre}^{+}$mutants, endothelial Fn1 was not sufficient to promote VSMC differentiation in the adjacent $\mathrm{NC}$, demonstrating the importance of NC cell-specific Fn1. Unlike in global Fn1-null embryos, NC cell survival and proliferation were not affected in the conditional $\mathrm{Fn} \mathrm{P}^{\text {flox/-}} ; \mathrm{Cre}^{+}$mutants, demonstrating that Fn1 synthesized by other embryonic cell types is sufficient to support NC proliferation and survival but not their differentiation into VSMCs.

Studies by Costa-Silva et al. (2009) showed that plating wild-type $\mathrm{NC}$ cells on plasma fibronectin-coated surfaces promoted the differentiation of NC cells into smooth muscle cells. Our data support these findings, since we observed only minimal smooth muscle differentiation of wild-type NC cells in the absence of plasma Fn1. However, we show that plasma Fn1 is not sufficient to rescue smooth muscle differentiation in Fn1-null NC cells. Together with the results of NC cell culture, our genetic studies in vivo demonstrate the requirement for the $\mathrm{NC}$ cell-specific source of Fn1 in the differentiation of NC cells into VSMCs.

Fn1 is alternatively spliced and we previously showed that the presence of EIIIA or EIIIB alternatively spliced exons in Fnl was necessary for $\mathrm{NC}$ development and cardiovascular morphogenesis (Astrof et al., 2007). However, both EIIIA ${ }^{+}$and EIIIB ${ }^{+}$forms of Fn1 are present around the PAAs (Astrof et al., 2007), and both the PAA endothelium and the NC synthesize EIIIB $^{+}$EIIIA $^{+}$Fn1 (our unpublished data). Thus, differences in the alternative splicing are unlikely to explain why endothelial Fn1 does not compensate for the absence of NC-synthesized Fn1. One would expect that in Fn $1^{\text {flox/- }}$; $\mathrm{Cre}^{+}$mutants, the total levels of Fn1 are lower at the interface of the PAA endothelium and the NC relative to controls; however, a simple decrease in Fn1 levels cannot explain defects observed in $\mathrm{Fn}^{\text {flox } /-}$; $\mathrm{Cre}^{+}$mutants, given that a $50 \%$ decrease in Fn1 protein levels is sufficient to support normal embryogenesis and adult homeostasis in $\mathrm{FnI}^{+/-}$mice. Addition of ectopic Fn1 (purified from either plasma or cellular sources) in vitro did not rescue NC-toVSMC differentiation in Fn1-deficient NC cells, supporting the notion that it is the synthesis of Fn1 by the NC that is important for VSMC differentiation of NC cells, rather than the overall levels of Fn1 protein. These results suggest that cell-autonomous and 

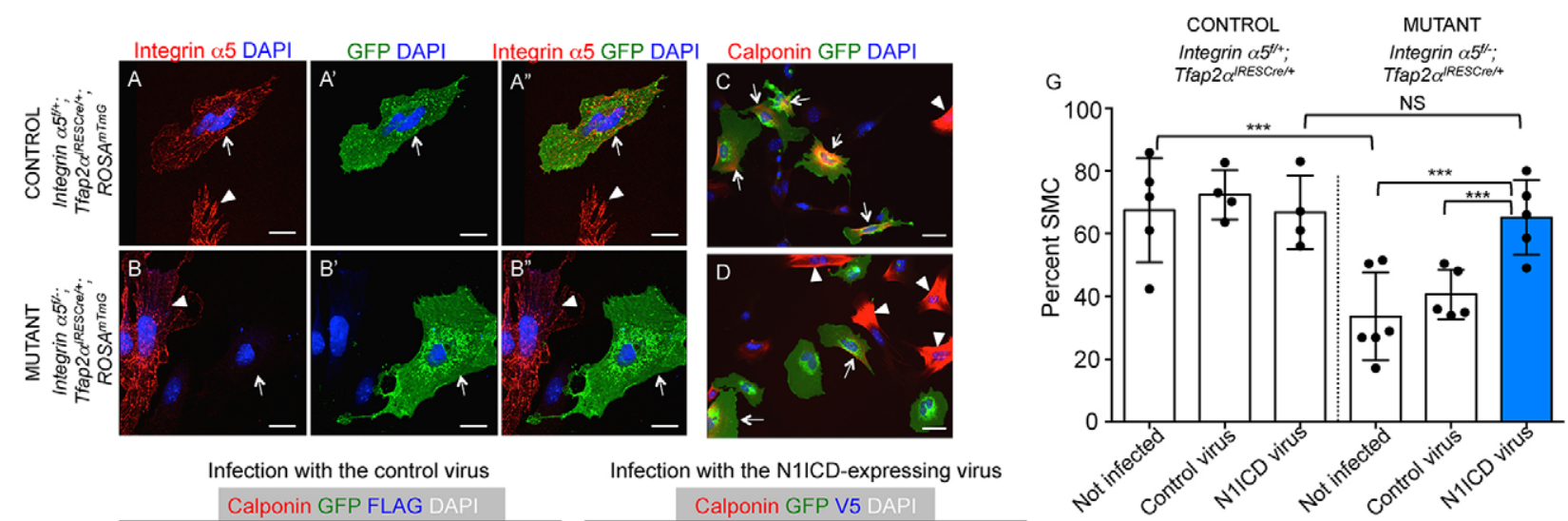

Infection with the control virus Calponin GFP FLAG D

Infection with the N1ICD-expressing virus Calponin GFP V5 DAPI
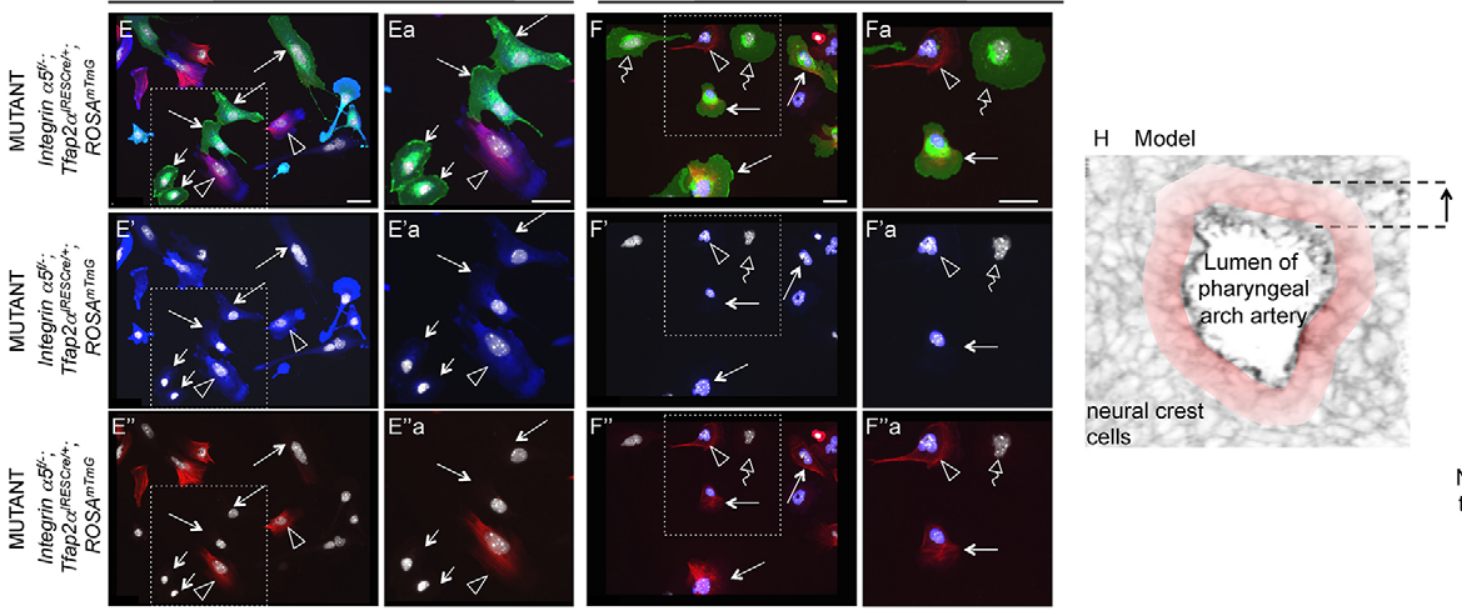

Induction of $\mathrm{Fn} 1$ expression in the NC by a hypothetical endothelial-derived morphogen*

Extent of $\mathrm{Fn} 1$ expression in the NC

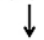

Extent of Notch activation in the NC

$\downarrow$

Number of NC cell layers around the $4^{\text {th }}$ PAA that differentiate into VSMCs

Fig. 7. Activation of Notch rescues smooth muscle differentiation in integrin- $-5-d e f i c i e n t ~ N C$ cells. (A-A") Control and (B-B") mutant NC cells (green, arrows) and mesodermal cells (arrowheads). Integrin $\alpha 5$ (red) and NC cells (GFP ${ }^{+}$, green), nuclei (DAPI, blue). (C,D) Control and integrin- $\alpha 5-$ deficient NC cells, stained for GFP (green) and calponin (red). Arrows indicate NC cells. GFP ${ }^{-}$mesodermal cells (arrowheads) act as internal positive controls for calponin staining. (E) Mutant NC cultures from pharyngeal arches 3-6 infected with adenovirus encoding control NDRG1-FLAG protein (blue). Arrows indicate NC cells (GFP ${ }^{+}$, green). Note that mesodermal cells (arrowheads) but not NC cells express calponin (red) in the mutant. The composite staining in $\mathrm{E}$ is split into separate channels in $E^{\prime}$ and $E^{\prime \prime}$; dashed boxes are magnified in Ea, $E^{\prime} a$ and $E^{\prime \prime} a$. (F) Mutant NC cells (GFP ${ }^{+}$, green) from the pharyngeal arches 3-6 infected with adenovirus encoding N1ICD (nuclear localized, blue). Straight arrows indicate infected NC cells, curved open arrows indicate non-infected NC cells and an arrowhead indicates a mesodermal cell. Note that N1ICD-infected mutant NC cells (straight arrows) but not the non-infected cells (curved open arrows) express calponin (red). The composite staining in $\mathrm{F}$ is split into separate channels in $\mathrm{F}^{\prime}$ and $\mathrm{F}^{\prime \prime}$, the dashed boxes are magnified in Fa, $\mathrm{F}^{\prime} \mathrm{a}$ and $\mathrm{F}^{\prime \prime} \mathrm{a}$. (G) Control or mutant $\mathrm{NC}$ cells were left non-infected or were infected with either control viruses or viruses expressing N1ICD. SMC differentiation was assayed by the detection of either $\alpha$ SMA or calponin. Statistics were performed using two-tailed, unpaired Student's $t$-test: ${ }^{* *} P<0.0053$; NS, not significant. Each data point is collected by analyzing NC cells isolated from one embryo. Mean and s.d. are plotted. For these experiments, we analyzed 798 non-infected controls NC cells isolated from 5 embryos, 575 control NC cells isolated from 4 embryos and infected with control virus, and 486 control NC cells isolated from 4 embryos and infected with N1ICD virus; 1201 non-infected mutant NC cells from 6 embryos, 716 mutant NC cells isolated from 5 embryos and infected with control virus, and 520 mutant NC cells isolated from 5 embryos infected with N1ICD virus. $(\mathrm{H})$ Model. We hypothesize that as the PAA endothelial lumen increases between E10.5 and E11.5 stages of development, endothelium is induced to secrete a diffusible factor regulating Fn1 expression in the NC-derived cells surrounding PAAs. This morphogen could also be in the form of mechanical force transduced from the endothelium to the NC due to the increased blood flow through the expanding PAA. *Morphogen could be a protein or mechanical force. Scale bars: $20 \mu \mathrm{m}$ in A-B"; $50 \mu \mathrm{m}$ in C,D; $40 \mu \mathrm{m}$ in E,F.

paracrine sources of Fn1 could engage different signaling pathways in the NC. Alternatively, differences between Fn1 proteins synthesized by the NC and endothelium could be due to potential variations in cell type-specific post-translational modifications of Fn1.

If NC-synthesized Fn1 signaled in an NC cell-autonomous manner, it would have to engage Fn1 receptors expressed by the NC (Testaz et al., 1999). Previous studies demonstrated that integrin $\alpha 5 \beta 1$ is a major Fn1 receptor in early and mid-gestation mouse embryos (Chen et al., 2015; George et al., 1997, 1993; Mittal et al., 2013, 2010; Pulina et al., 2014, 2011; Takahashi et al., 2007; Yang et al., 1999, 1993). Therefore, we used conditional mutagenesis to ablate integrin $\alpha 5$ in the NC. These studies showed that the expression of integrin $\alpha 5 \beta 1$ by NC cells was required to facilitate the differentiation of NC cells into VSMCs. Thus, our experiments suggested that NC-synthesized Fn1 regulates the differentiation of $\mathrm{NC}$ cells into VSMCs by engaging integrin $\alpha 5 \beta 1$ expressed by NC cells in a cell-autonomous manner.

Much of what we know about the roles of Fn1 in cell biology has been gleaned from studies with ectopically supplied purified Fn1 proteins (Bae et al., 2014; Hynes, 1990; Schwartz, 2010). However, recent in vivo studies suggest that in addition to paracrine functions (Yoshino et al., 2014), Fn1 could also signal in a cell-autonomous manner (Cseh et al., 2010; Liu et al., 2010; Serres et al., 2014; Stenzel et al., 2011). By using genetic and cell biological approaches, the studies reported in this paper are the first to demonstrate the requisite, cell-autonomous role of Fn1 in the regulation of cardiovascular development. This discovery bears 
significant implications for the fields of regenerative biology and tissue engineering by demonstrating that cell-specific synthesis of ECM can modulate distinct aspects of organ morphogenesis and that simply providing ECM in trans as an adhesive support may not elicit the appropriate cell signaling responses.

\section{Early and late roles of Fn1-binding integrins in AAA morphogenesis}

In our studies, we used mouse strains, in which the Cre recombinase is expressed early in the $\mathrm{NC}$ development ( $\sim 5$ somite stage) (Lewis et al., 2013; Olaopa et al., 2011; Stottmann et al., 2004); this is before the delamination of cardiac NC cells and prior to their arrival into the pharyngeal arches. Thus, our studies specifically address the role of Fn 1 and integrin $\alpha 5$ in the differentiation of multi-potent NC cells into VSMCs. By contrast, Turner et al. (2015) used the $S M 22 \alpha$ Cre transgenic line to ablate integrins $\alpha 5$ and $\alpha \mathrm{v}$ in smooth muscle lineages, including those derived from the NC. SM22 $\alpha$ is a marker of early smooth muscle differentiation. Thus, the downregulation of integrins $\alpha 5$ and $\alpha \mathrm{v}$ in Itga5/Itgav ${ }^{\text {SM22-Cre }}$ double mutants has most likely occurred after the onset of VSMC differentiation in the $\mathrm{NC}$, explaining the lack of VSMC differentiation defect in these mutants (Turner et al., 2015). Similarly, Turlo et al. (2012) used the SM22 $\alpha$ Cre transgenic line to ablate integrin $\beta 1$ and showed that the expression of $\beta 1$-containing integrin heterodimers, which include $\alpha 5 \beta 1$, in smooth muscle cells was important for maintaining AAA VSMCs and AAA integrity. Taken together with the studies by Turlo et al. (2012) and Turner et al. (2015), our work demonstrates that signaling by Fn1 and integrin $\alpha 5 \beta 1$ is essential for both the morphogenesis and maintenance of the AAAs: our studies establish the requisite role of $\mathrm{Fn} 1$ and integrin $\alpha 5 \beta 1$ in the differentiation of $\mathrm{NC}$ cells into VSMCs, thereby regulating the remodeling of symmetrical PAAs into the AAAs. The work of Turlo et al. (2012) and Turner et al. (2015) demonstrated that following the differentiation of $\mathrm{NC}$ cells into VSMCs, signaling by $\alpha 5-, \alpha \mathrm{V}$ and $\beta 1$-containing integrin heterodimers is essential for maintaining VSMCs and the architecture of the AAA vessel wall.

\section{The role of Fn1 and integrin $\alpha 5$ in VSMC development depends on the ontogeny of VSMC progenitors}

VSMCs in diverse vascular beds arise from different progenitors. Known embryonic sources of VSMCs include the lateral and paraxial mesoderm, mesothelia and the NC (Jiang et al., 2000; Le Lievre and Le Douarin, 1975; Que et al., 2008; Rinkevich et al., 2012; Wasteson et al., 2008; Wilm et al., 2005). Studies by others and our lab indicated that integrin $\alpha 5$ is not required for the differentiation of mesodermal cells into VSMCs (Liang et al., 2014; Turner et al., 2014, 2015). Furthermore, addition of Fn1 to mesodermal VSMC precursors stimulated their proliferation and the synthetic phenotype and opposed their differentiation into smooth muscle cells (Bae et al., 2014; Hedin et al., 1988; Shi et al., 2014). This contrasts with the roles of Fn1 and integrin $\alpha 5$ in the differentiation of NC cells. Currently, it is not clear why signaling by Fn1 and integrin $\alpha 5$ differs between mesoderm- and NC-derived VSMC progenitors. However, it is widely known that VSMCs from different tissue sources can be distinguished on the basis of their gene expression profiles, the mechanisms regulating their differentiation and in their susceptibility to disease and injury (Cheung et al., 2012; Gittenberger-de Groot et al., 1999; Majesky, 2007; Michel et al., 2012; Pfaltzgraff et al., 2014; Ruddy et al., 2008). Furthermore, differences in genetic regulation of VSMC development between the mesoderm and NC contribute to pathological manifestations of congenital disorders such as Marfan and Loeys-Dietz syndromes, both of which involve aneurisms that develop at the borders of mesoderm- and NC-derived VSMCs (Majesky et al., 2011; Ruddy et al., 2008). In the future, it will be instrumental to determine the mechanisms underlying distinct functions of Fn1 and integrin $\alpha 5$ in the differentiation of VSMCs from mesodermal and $\mathrm{NC}$ progenitors.

\section{Fn1 and integrin $\alpha 5 \beta 1$ regulate the differentiation of NC cells into VSMCs by activating Notch signaling}

Activation of Notch signaling in NC cells surrounding the PAAs is essential for the differentiation of NC cells into VSCMs (High et al., 2008, 2007; Manderfield et al., 2012). In this paper, we show that Notch activation is limited to the field of NC cells expressing $F n 1$ and that Fn1 facilitates activation of Notch by signaling through integrin $\alpha 5 \beta 1$. How interactions between Fn1 and integrin $\alpha 5 \beta 1$ regulate Notch signaling is not yet clear. However, it is known that signaling by integrins can regulate Notch activation both directly and indirectly. In Drosophila, integrin heterodimers containing $\beta 1$ regulate Notch activation by regulating its intracellular trafficking or processing (Gomez-Lamarca et al., 2014). Studies in Drosophila also showed that the activation of Notch occurs at the tips of basal filopodia and requires the activation of ezrin, Rac, Scar and actin polymerization (Cohen et al., 2010; De Joussineau et al., 2003). Signaling by Fn1 and $\alpha 5 \beta 1$ is well known to activate Rac, the Wave/Scar complex and actin polymerization (reviewed by Huttenlocher and Horwitz, 2011). Thus, ablation of Fn 1 or integrin $\alpha 5$ in the NC could interfere with Notch signaling by interfering with actin polymerization, formation of basal filopodia, or by altering the trafficking/ processing of Notch. An indirect role of $\beta 1$-containing integrin heterodimers in the activation of Notch was demonstrated in the chick (Rallis et al., 2010). These studies showed that $\beta 1$ integrins activate Jagged1 transcription through ILK-mediated stabilization of $\beta$-catenin. Stabilized $\beta$-catenin directly binds and activates Jagged1 promoters upon translocation into the nucleus (Estrach et al., 2006; Rallis et al., 2010). This is consistent with our observations that Notch signaling is active in cells that express Fn1, and that Notch signaling declines concomitant with the decrease in Fn1 levels.

Taken together, our studies highlight the requisite role of the NCspecific source of Fn1 during morphogenesis of the aortic arch arteries and raise many interesting questions: do $\mathrm{NC}$ - and endothelial-derived forms of Fn1 differ from each other? Do paracrine and autocrine sources of Fn1 engage different cellular signaling pathways? What are the mechanisms regulating FnI expression in the NC and what are the intracellular pathways by which Fn1 and integrin $\alpha 5 \beta 1$ regulate Notch signaling?

\section{MATERIALS AND METHODS}

\section{Mouse strains and genotyping}

Details of mouse strains used can be found in supplementary Materials and Methods. Genotyping was performed using PCR primers as described previously (Mittal et al., 2010; Sakai et al., 2001; van der Flier et al., 2010). All embryos up to E10.5 were staged by counting somites, older embryos were staged by the day of vaginal plug. All animal studies were approved by the Thomas Jefferson University Institutional Animal Care and Use Committee.

\section{Histology}

Histology, immunohistochemistry and $\beta$-gal staining were performed as described previously (Chen et al., 2015; Liang et al., 2014). For more details about the procedures and antibodies, see supplementary Materials and Methods. 


\section{In situ hybridization}

In situ hybridization was carried out using Fnl (316951), Heyl (319021), Hey2 (404651), Notch1 (404641) and Notch3 (425171) RNA probes synthesized by Advanced Cell Diagnostics (ACD). Detection was done using RNAscope 2.0 FFPE Assay Brown kit according to the manufacturer's protocol (ACD). After the signal was developed, sections were counterstained with Gill's hematoxylin.

\section{Quantification of vessel coverage by VSMCs}

VSMC coverage (Figs S4 and S5) was determined using coronal sections from control and mutant embryos dissected at E11.5. Quantification of 4-18 sections per pharyngeal arch per embryo was performed using ImageJ software. Equivalent numbers of sections were analyzed for each set composed of one control and one mutant embryo and 5-6 sets of control and mutant embryos were analyzed per experiment. To determine VSMC coverage, we calculated the fraction of vessel perimeter occupied by $\alpha \mathrm{SMA}^{+}$ or SM $22 \alpha^{+}$signal.

\section{Neural tube explant culture and immunofluorescent staining of NC cells}

Control and mutant embryos were obtained by crossing $\mathrm{FnI}^{+/-}$, Tfap $2^{\text {IRESCre }}$ females with Fn $1^{\text {floxfllox }} ; R_{O S A}{ }^{m T / m G}$ male mice. E8.5 embryos (15 somites) were dissected in PBS. To obtain integrin- $\alpha 5$ deficient NC cells and their controls, we crossed Itga $5^{+/} ;$Tfap $2 a^{\text {IRESCre }}$ or Itga $5^{+/-} ;$P3Pro-Cre females with Itga $5^{\text {flox/flox }} ; R_{O S A}{ }^{m T / m G}$ male mice. The neural tube (NT) from the otic placode to the fourth somite was dissected out and incubated in collagenase/dispase $(100 \mu \mathrm{g} / \mathrm{ml}$; Roche, 11097113001) for $7 \mathrm{~min}$ at room temperature. The neural tube was microdissected from the surrounding mesenchyme and the surface ectoderm, and then longitudinally plated on $12 \mathrm{~mm}$ glass coverslips pre-coated with $100 \mu \mathrm{g} / \mathrm{ml}$ collagen type I (BD Biosciences, 354249) in 4-well plates (Thermo Scientific, 12-566350). To induce smooth muscle differentiation, explants were cultured for 3 days at $37^{\circ} \mathrm{C}$ and $5 \% \mathrm{CO}_{2}$ in high glucose DMEM (Invitrogen) containing $10 \%$ fetal bovine serum (BenchMark FBS, Gemini Bio-Products).

To culture NC cells from the pharyngeal arches 3-6 isolated from E9.5 mouse embryos, embryos were incubated with $150 \mu \mathrm{g} / \mathrm{ml}$ collagenase/ dispase for $3 \mathrm{~min}$. Surface ectoderm was peeled off and pharyngeal arches 3 6 were dissected out, plated as above, then cultured in NC self-renewal medium for 4 days (Bixby et al., 2002). On the 5th day, NC cultures were digested using $0.25 \%$ trypsin into single cells and plated on $12 \mathrm{~mm}$ glass coverslips pre-coated with either $150 \mu \mathrm{g} / \mathrm{ml}$ collagen I, $10 \mu \mathrm{g} / \mathrm{ml}$ plasma Fn1 (BD Biosciences, 356008) or $10 \mu \mathrm{g} / \mathrm{ml}$ cellular Fn1 (Sigma, F2518). We confirmed that cellular Fn1 but not plasma Fn1 contained the EIIIA domain by western blotting using anti-EIIIA antibody (Sigma, F6140).

\section{Smooth muscle differentiation conditions and quantification}

To induce smooth muscle differentiation, cells were cultured in DMEM containing $10 \% \mathrm{FBS}$ at $37^{\circ} \mathrm{C}$ and $5 \% \mathrm{CO}_{2}$ until all cells attached $(2 \mathrm{~h})$. After this, $\mathrm{NC}$ cells were either left in the medium for the additional $48 \mathrm{~h}$ or treated with adenoviruses (see below) for 2 days. Cells were then fixed in 4\% PFA for $20 \mathrm{~min}$ at room temperature, washed and blocked for $30 \mathrm{~min}$ with $10 \%$ normal donkey serum in PBS $/ 0.05 \%$ Tween-20. Cells were incubated overnight at $4{ }^{\circ} \mathrm{C}$ with primary antibodies diluted in blocking buffer. After a thorough washing step the next day, cells were incubated for $1 \mathrm{~h}$ at room temperature with secondary antibodies and mounted with ProLong Gold antifade. Images were captured with a Zeiss Axiovert inverted fluorescence microscope.

$\mathrm{NC}$ cultures were stained to identify $\mathrm{NC}$-derived cells $\left(\mathrm{GFP}^{+}\right.$, due to the presence of $R O S A^{m T m G}$ reporter allele), smooth muscle cells ( $\alpha$ SMA or calponin 1) and DAPI (nuclei). For infected cultures, cells were also stained to identify infected cells using antibodies directed against either the FLAG or V5 tags (for further details see supplementary Materials and Methods). All cells in each well were photographed at $20 \times$ magnification and coded to conceal the identity of $\mathrm{NC}$ cell genotypes. The data were quantified without the knowledge of genotypes. Following quantification, the identity of the samples was decoded and results were analyzed using Prism 6 software (GraphPad). To quantify differentiation of untreated control and integrin- $\alpha 5$-deficient NC cells or NC cells infected with control or N1ICDencoding viruses, we performed at least four independent experiments, all plotted in Fig. $7 \mathrm{G}$.

\section{Adenoviral infection}

Adenoviruses expressing V5-tagged Notch 1 intracellular domain (N1ICD) were produced by the Viral Vector Core at the Maine Medical Center Research Institute (Tang et al., 2008). The N1ICD virus stock concentration was $1.3 \times 10^{13}$ viral particles $/ \mathrm{ml}$. Control adenoviruses were produced using RAPAd CMV adenoviral expression system (Cell Biolabs, San Diego, CA, USA). Stock adenoviral concentration was $4 \times 10^{11} \mathrm{pfu} / \mathrm{ml}$. Viral stock solutions were diluted 1:1000 in DMEM containing 10\% FBS and $300 \mu \mathrm{l}$ was used to infect the cells. Viruses were incubated with $\mathrm{NC}$ cells at $37^{\circ} \mathrm{C}$ and $5 \% \mathrm{CO}_{2}$ for $48 \mathrm{~h}$. Cells where then fixed for $20 \mathrm{~min}$ with $4 \%$ PFA at room temperature, washed with PBS and stained using antibodies against GFP, $\alpha$ SMA or calponin, and V5 or FLAG tags.

\section{Statistics}

Data were analyzed by two-tailed, unpaired Student's $t$-tests or by two-way ANOVA, as indicated in figure legends utilizing Prism $6 \mathrm{GraphPad}$ software. A $P$-value of less than 0.05 was considered significant.

\section{Acknowledgements}

We are grateful to Dr Anne Moon for TFAP $2 \alpha^{I R E S C r e}$ mice, Dr Jeff Miner for providing P3Pro-Cre transgenic mice, which were generated in Dr Jon Epstein's lab,

Dr Richard Hynes for providing integrin $\alpha 5$ floxed mice prior to their publication, and Dr Reinhardt Fassler for Fn1 floxed mice. We thank Dr Karl Degenhardt for help with the interpretation of cardiac phenotypes and Dr Marion Cooley for the anti-Fibulin1 antibody. We thank Shuan-Yu Hou, Ahab Dababneh and Sonam Dhiman for technical assistance, and Dr Maria Yolanda Covarrubias of the Kimmel Cancer Center Bioimaging facility at the Thomas Jefferson University for assistance with confocal imaging. We thank Dr Jianxin Sun and the members of his laboratory for assistance with generating adenoviruses and for providing control adenoviruses used in these experiments. We thank Dr Igor A. Prudovsky for providing N1ICD adenoviral expression vector and Dr Nancy Chandler-Conrey and the Viral Vector Core at the Maine Medical Center Research Institute for production of N1ICD adenoviruses. We are grateful to Dr Nathan Astrof for critical reading of the manuscript, helpful discussion, and insightful suggestions. We also thank Tung Chan, Glenn Radice, Mary Hutson and Joshua Brickman for critical reading of the manuscript. We are especially grateful to Sydney Astrof for her curiosity and energy. We thank Jennifer Wilson from the TJU Writing Center for editorial assistance.

\section{Competing interests}

The authors declare no competing or financial interests.

\section{Author contributions}

Conceived and designed experiments: X.W. and S.A. Performed experiments: X.W. Analyzed data and generated figures: X.W. and S.A. Wrote the paper: X.W. and S.A.

Funding

This work was supported by the funding from the National Institutes of Health [NHLBI RO1 HL103920 to S.A.], American Heart Association Innovative Research Grant [12IRG9130012 to S.A.], the W. W. Smith Charitable Trust, and the funds from the Weizmann Institute of Science - Thomas Jefferson University Collaboration Program to S.A. X.W. was supported by an American Heart Association Postdoctoral Fellowship [12POST11750033 to X.W.]. Deposited in PMC for release after 12 months.

\section{Supplementary information}

Supplementary information available online at

http://dev.biologists.org/lookup/suppl/doi:10.1242/dev.125286/-/DC1

\section{References}

Arnold, T. D., Zang, K. and Vallejo-Illarramendi, A. (2013). Deletion of integrinlinked kinase from neural crest cells in mice results in aortic aneurysms and embryonic lethality. Dis. Model. Mech. 6, 1205-1212.

Assoian, R. K. and Schwartz, M. A. (2001). Coordinate signaling by integrins and receptor tyrosine kinases in the regulation of $\mathrm{G} 1$ phase cell-cycle progression. Curr. Opin. Genet. Dev. 11, 48-53.

Astrof, S. (2013). Interactions between neural crest-derived cells and extracellular microenvironment during cardiovascular development. In Extracellular Matrix in Development (ed. D. W. Desimone and R. P. Mecham), pp. 105-131. Berlin Springer Verlag. 
Astrof, S., Crowley, D. and Hynes, R. O. (2007). Multiple cardiovascular defects caused by the absence of alternatively spliced segments of fibronectin. Dev. Biol. 311, 11-24

Bae, Y. H., Mui, K. L., Hsu, B. Y., Liu, S.-L., Cretu, A., Razinia, Z., Xu, T., Pure, E. and Assoian, R. K. (2014). A FAK-Cas-Rac-lamellipodin signaling module transduces extracellular matrix stiffness into mechanosensitive cell cycling. Sci. Signal. 7, ra57.

Bockman, D. E. and Kirby, M. L. (1984). Dependence of thymus development on derivatives of the neural crest. Science 223, 498-500.

Bordeleau, F., Califano, J. P., Negron Abril, Y. L., Mason, B. N., LaValley, D. J., Shin, S. J., Weiss, R. S. and Reinhart-King, C. A. (2015). Tissue stiffness regulates serine/arginine-rich protein-mediated splicing of the extra domain B-fibronectin isoform in tumors. Proc. Natl. Acad. Sci. USA 112, 8314-8319.

Boucher, J. M., Peterson, S. M., Urs, S., Zhang, C. and Liaw, L. (2011). The miR$143 / 145$ cluster is a novel transcriptional target of Jagged-1/Notch signaling in vascular smooth muscle cells. J. Biol. Chem. 286, 28312-28321.

Chan, W. Y., Cheung, C. S., Yung, K. M. and Copp, A. J. (2004). Cardiac neural crest of the mouse embryo: axial level of origin, migratory pathway and cell autonomy of the splotch $(\mathrm{Sp} 2 \mathrm{H})$ mutant effect. Development 131, 3367-3379.

Chen, Y., Moon, A. M. and Gaufo, G. O. (2012). Influence of mesodermal Fgf8 on the differentiation of neural crest-derived postganglionic neurons. Dev. Biol. 361 125-136.

Chen, D., Wang, X., Liang, D., Gordon, J., Mittal, A., Manley, N. R., Degenhardt, K. and Astrof, S. (2015). Fibronectin signals through integrin $\alpha 5 \beta 1$ to regulate cardiovascular development in a cell type-specific manner. Dev. Biol. 407, 195-210.

Cheung, C., Bernardo, A. S., Trotter, M. W. B., Pedersen, R. A. and Sinha, S (2012). Generation of human vascular smooth muscle subtypes provides insight into embryological origin-dependent disease susceptibility. Nat. Biotechnol. $\mathbf{3 0}$, 165-173.

Chiquet, M., Renedo, A. S., Huber, F. and Flück, M. (2003). How do fibroblasts translate mechanical signals into changes in extracellular matrix production? Matrix Biol. 22, 73-80.

Cohen, M., Georgiou, M., Stevenson, N. L., Miodownik, M. and Baum, B. (2010) Dynamic filopodia transmit intermittent Delta-Notch signaling to drive pattern refinement during lateral inhibition. Dev. Cell. 19, 78-89.

Conway, S. J., Kruzynska-Frejtag, A., Kneer, P. L., Machnicki, M. and Koushik S. V. (2003). What cardiovascular defect does my prenatal mouse mutant have, and why? Genesis 35, 1-21.

Cooley, M. A., Kern, C. B., Fresco, V. M., Wessels, A., Thompson, R. P., McQuinn, T. C., Twal, W. O., Mjaatvedt, C. H., Drake, C. J. and Argraves, W. S. (2008). Fibulin-1 is required for morphogenesis of neural crest-derived structures. Dev. Biol. 319, 336-345.

Costa-Silva, B., da Costa, M. C., Melo, F. R., Neves, C. M., Alvarez-Silva, M., Calloni, G. W. and Trentin, A. G. (2009). Fibronectin promotes differentiation of neural crest progenitors endowed with smooth muscle cell potential. Exp. Cell Res. 315, 955-967

Crane, J. F. and Trainor, P. A. (2006). Neural crest stem and progenitor cells. Annu. Rev. Cell Dev. Biol. 22, 267-286.

Cseh, B., Fernandez-Sauze, S., Grall, D., Schaub, S., Doma, E. and Van Obberghen-Schilling, E. (2010). Autocrine fibronectin directs matrix assembly and crosstalk between cell-matrix and cell-cell adhesion in vascular endothelia cells. J. Cell Sci. 123, 3989-3999.

De Joussineau, C., Soulé, J., Martin, M., Anguille, C., Montcourrier, P. and Alexandre, D. (2003). Delta-promoted filopodia mediate long-range latera inhibition in Drosophila. Nature 426, 555-559.

Doi, H., Iso, T., Sato, H., Yamazaki, M., Matsui, H., Tanaka, T., Manabe, I., Arai, M., Nagai, R. and Kurabayashi, M. (2006). Jagged1-selective notch signaling induces smooth muscle differentiation via a RBP-Jkappa-dependent pathway. J. Biol. Chem. 281, 28555-28564

Donoghue, P. C. J., Graham, A. and Kelsh, R. N. (2008). The origin and evolution of the neural crest. Bioessays 30,530-541.

Eddison, M., Le Roux, I. and Lewis, J. (2000). Notch signaling in the development of the inner ear: lessons from Drosophila. Proc. Natl. Acad. Sci. USA 97, 11692-11699.

Estrach, S., Ambler, C. A., Lo Celso, C., Hozumi, K. and Watt, F. M. (2006) Jagged 1 is a beta-catenin target gene required for ectopic hair follicle formation in adult epidermis. Development 133, 4427-4438.

Ferguson, C. A. and Graham, A. (2004). Redefining the head-trunk interface for the neural crest. Dev. Biol. 269, 70-80.

Gao, Z., Kim, G. H., Mackinnon, A. C., Flagg, A. E., Bassett, B., Earley, J. U. and Svensson, E. C. (2010). Ets1 is required for proper migration and differentiation of the cardiac neural crest. Development 137, 1543-1551.

George, E. L., Georges-Labouesse, E. N., Patel-King, R. S., Rayburn, H. and Hynes, R. O. (1993). Defects in mesoderm, neural tube and vascula development in mouse embryos lacking fibronectin. Development 119, 1079-1091.

George, E. L., Baldwin, H. S. and Hynes, R. O. (1997). Fibronectins are essential for heart and blood vessel morphogenesis but are dispensable for initial specification of precursor cells. Blood 90, 3073-3081.
Giancotti, F. G. and Tarone, G. (2003). Positional control of cell fate through join integrin/receptor protein kinase signaling. Annu. Rev. Cell Dev. Biol. 19, 173-206 Gittenberger-de Groot, A. C., DeRuiter, M. C., Bergwerff, M. and Poelmann, R. E. (1999). Smooth muscle cell origin and its relation to heterogeneity in development and disease. Arterioscler. Thromb. Vasc. Biol. 19, 1589-1594.

Go, A. S., Mozaffarian, D., Roger, V. L., Benjamin, E. J., Berry, J. D., Borden, W. B., Bravata, D. M., Dai, S., Ford, E. S., Fox, C. S. et al. (2013). Heart disease and stroke statistics-2013 update: a report from the American Heart Association. Circulation 127, e6-e245

Gomez-Lamarca, M. J., Cobreros-Reguera, L., Ibanez-Jimenez, B., Palacios, I. M. and Martin-Bermudo, M. D. (2014). Integrins regulate epithelial cell differentiation by modulating Notch activity. J. Cell Sci. 127, 4667-4678.

Grazioli, A., Alves, C. S., Konstantopoulos, K. and Yang, J. T. (2006). Defective blood vessel development and pericyte/pvSMC distribution in alpha 4 integrindeficient mouse embryos. Dev. Biol. 293, 165-177.

Haack, H. and Hynes, R. O. (2001). Integrin receptors are required for cell survival and proliferation during development of the peripheral glial lineage. Dev. Biol. 233 38-55.

Hedin, U., Bottger, B. A., Forsberg, E., Johansson, S. and Thyberg, J. (1988) Diverse effects of fibronectin and laminin on phenotypic properties of cultured arterial smooth muscle cells. J. Cell Biol. 107, 307-319.

High, F. A. and Epstein, J. A. (2008). The multifaceted role of Notch in cardiac development and disease. Nat. Rev. Genet. 9, 49-61.

High, F. A., Zhang, M., Proweller, A., Tu, L., Parmacek, M. S., Pear, W. S. and Epstein, J. A. (2007). An essential role for Notch in neural crest during cardiovascular development and smooth muscle differentiation. J. Clin. Invest 117, 353-363.

High, F. A., Lu, M. M., Pear, W. S., Loomes, K. M., Kaestner, K. H. and Epstein, J. A. (2008). Endothelial expression of the Notch ligand Jagged1 is required fo vascular smooth muscle development. Proc. Natl. Acad. Sci. USA 105, 1955-1959.

Hutson, M. R. and Kirby, M. L. (2007). Model systems for the study of heart development and disease: cardiac neural crest and conotruncal malformations. Semin. Cell Dev. Biol. 18, 101-110.

Huttenlocher, A. and Horwitz, A. R. (2011). Integrins in cell migration. Cold Spring Harb. Perspect. Biol. 3, a005074.

Hynes, R. O. (1990). Fibronectins. New York: Springer-Verlag.

Hynes, R. O. (2002). Integrins: bidirectional, allosteric signaling machines. Cell 110 , 673-687.

Hynes, R. O. (2012). Evolution: the evolution of metazoan extracellular matrix. J. Cell Biol. 196, 671-679.

Itasaki, N., Sharpe, J., Morrison, A. and Krumlauf, R. (1996). Reprogramming Hox expression in the vertebrate hindbrain: influence of paraxial mesoderm and rhombomere transposition. Neuron 16, 487-500.

Jiang, X., Rowitch, D. H., Soriano, P., McMahon, A. P. and Sucov, H. M. (2000). Fate of the mammalian cardiac neural crest. Development 127, 1607-1616.

Kaartinen, V., Dudas, M., Nagy, A., Sridurongrit, S., Lu, M. M. and Epstein, J. A (2004). Cardiac outflow tract defects in mice lacking ALK2 in neural crest cells. Development 131, 3481-3490.

Le Douarin, N. M. and Kalcheim, C. (1999). The Neural Crest, 445 pp. Cambridge: Cambridge University Press.

Le Lievre, C. S. and Le Douarin, N. M. (1975). Mesenchymal derivatives of the neural crest: analysis of chimaeric quail and chick embryos. J. Embryol. Exp. Morphol. 34, 125-154

Leatherbury, L., Gauldin, H. E., Waldo, K. and Kirby, M. L. (1990) Microcinephotography of the developing heart in neural crest-ablated chick embryos. Circulation 81, 1047-1057

Lewis, A. E., Vasudevan, H. N., O'Neill, A. K., Soriano, P. and Bush, J. O. (2013) The widely used Wnt1-Cre transgene causes developmental phenotypes by ectopic activation of Wnt signaling. Dev. Biol. 379, 229-234.

Li, J., Chen, F. and Epstein, J. A. (2000). Neural crest expression of Cre recombinase directed by the proximal Pax3 promoter in transgenic mice. Genesis 26, 162-164

Li, J., Zhu, X., Chen, M., Cheng, L., Zhou, D., Lu, M. M., Du, K., Epstein, J. A. and Parmacek, M. S. (2005). Myocardin-related transcription factor B is required in cardiac neural crest for smooth muscle differentiation and cardiovascula development. Proc. Natl. Acad. Sci. USA 102, 8916-8921.

Liang, D., Wang, X., Mittal, A., Dhiman, S., Hou, S.-Y., Degenhardt, K. and Astrof, S. (2014). Mesodermal expression of integrin alpha5beta1 regulates neural crest development and cardiovascular morphogenesis. Dev. Biol. 395 232-244.

Liu, C., Yao, J., Mercola, D. and Adamson, E. (2000). The transcription factor EGR-1 directly transactivates the fibronectin gene and enhances attachment of human glioblastoma cell line U251. J. Biol. Chem. 275, 20315-20323.

Liu, K., Cheng, L., Flesken-Nikitin, A., Huang, L., Nikitin, A. Y. and Pauli, B. U. (2010). Conditional knockout of fibronectin abrogates mouse mammary gland lobuloalveolar differentiation. Dev. Biol. 346, 11-24.

Macatee, T. L., Hammond, B. P., Arenkiel, B. R., Francis, L., Frank, D. U. and Moon, A. M. (2003). Ablation of specific expression domains reveals discrete 
functions of ectoderm- and endoderm-derived FGF8 during cardiovascular and pharyngeal development. Development 130, 6361-6374.

Majesky, M. W. (2007). Developmental basis of vascular smooth muscle diversity. Arterioscler. Thromb. Vasc. Biol. 27, 1248-1258.

Majesky, M. W., Dong, X. R. and Hoglund, V. J. (2011). Parsing aortic aneurysms: more surprises. Circ. Res. 108, 528-530.

Manderfield, L. J., High, F. A., Engleka, K. A., Liu, F., Li, L., Rentschler, S. and Epstein, J. A. (2012). Notch activation of Jagged1 contributes to the assembly of the arterial wall. Circulation 125, 314-323.

Manderfield, L. J., Aghajanian, H., Engleka, K. A., Lim, L. Y., Lui, F., Jain, R., Li, L., Olson, E. N. and Epstein, J. A. (2015). Hippo signaling is required for Notchdependent smooth muscle differentiation of neural crest. Development 142 , 2962-2971

Michel, J.-B., Li, Z. and Lacolley, P. (2012). Smooth muscle cells and vascular diseases. Cardiovasc. Res. 95, 135-137.

Mittal, A., Pulina, M., Hou, S.-Y. and Astrof, S. (2010). Fibronectin and integrin alpha 5 play essential roles in the development of the cardiac neural crest. Mech. Dev. 127, 472-484

Mittal, A., Pulina, M., Hou, S.-Y. and Astrof, S. (2013). Fibronectin and integrin alpha 5 play requisite roles in cardiac morphogenesis. Dev. Biol. 381, 73-82.

Moon, A. M. (2006). Mouse models for investigating the developmental basis of human birth defects. Pediatr. Res. 59, 749-755.

Moon, A. (2008). Mouse models of congenital cardiovascular disease. Curr. Top. Dev. Biol. 84, 171-248.

Muzumdar, M. D., Tasic, B., Miyamichi, K., Li, L. and Luo, L. (2007). A global double-fluorescent Cre reporter mouse. Genesis 45, 593-605.

Nishibatake, M., Kirby, M. L. and Van Mierop, L. H. (1987). Pathogenesis of persistent truncus arteriosus and dextroposed aorta in the chick embryo after neural crest ablation. Circulation 75, 255-264.

Noseda, M., Fu, Y., Niessen, K., Wong, F., Chang, L., McLean, G. and Karsan, A (2006). Smooth Muscle alpha-actin is a direct target of Notch/CSL. Circ. Res. 98, 1468-1470

Oh, J., Richardson, J. A. and Olson, E. N. (2005). Requirement of myocardinrelated transcription factor-B for remodeling of branchial arch arteries and smooth muscle differentiation. Proc. Natl. Acad. Sci. USA 102, 15122-15127.

Olaopa, M., Zhou, H.-M., Snider, P., Wang, J., Schwartz, R. J., Moon, A. M. and Conway, S. J. (2011). Pax3 is essential for normal cardiac neural crest morphogenesis but is not required during migration nor outflow tract septation. Dev. Biol. 356, 308-322.

Peters, J. H. and Hynes, R. O. (1996). Fibronectin isoform distribution in the mouse I. The alternatively spliced EIIIB, EIIIA, and V segments show widespread codistribution in the developing mouse embryo. Cell Adhes. Commun. 4, 103-125.

Pfaltzgraff, E. R., Shelton, E. L., Galindo, C. L., Nelms, B. L., Hooper, C. W., Poole, S. D., Labosky, P. A., Bader, D. M. and Reese, J. (2014). Embryonic domains of the aorta derived from diverse origins exhibit distinct properties that converge into a common phenotype in the adult. J. Mol. Cell. Cardiol. 69, 88-96.

Porras, D. and Brown, C. B. (2008). Temporal-spatial ablation of neural crest in the mouse results in cardiovascular defects. Dev. Dyn. 237, 153-162.

Pulina, M. V., Hou, S.-Y., Mittal, A., Julich, D., Whittaker, C. A., Holley, S. A. Hynes, R. O. and Astrof, S. (2011). Essential roles of fibronectin in the development of the left-right embryonic body plan. Dev. Biol. 354, 208-220.

Pulina, M., Liang, D. and Astrof, S. (2014). Shape and position of the node and notochord along the bilateral plane of symmetry are regulated by cell-extracellular matrix interactions. Biol. Open 3, 583-590

Que, J., Wilm, B., Hasegawa, H., Wang, F., Bader, D. and Hogan, B. L. M. (2008) Mesothelium contributes to vascular smooth muscle and mesenchyme during lung development. Proc. Natl. Acad. Sci. USA 105, 16626-16630.

Rallis, C., Pinchin, S. M. and Ish-Horowicz, D. (2010). Cell-autonomous integrin control of Wnt and Notch signalling during somitogenesis. Development 137, 3591-3601.

Rinkevich, Y., Mori, T., Sahoo, D., Xu, P.-X., Bermingham, J. R., Jr and Weissman, I. L. (2012). Identification and prospective isolation of a mesothelia precursor lineage giving rise to smooth muscle cells and fibroblasts for mammalian internal organs, and their vasculature. Nat. Cell Biol. 14, 1251-1260.

Ross, D. A. and Kadesch, T. (2004). Consequences of Notch-mediated induction of Jagged1. Exp. Cell Res. 296, 173-182.

Ruddy, J. M., Jones, J. A., Spinale, F. G. and Ikonomidis, J. S. (2008). Regional heterogeneity within the aorta: relevance to aneurysm disease. J. Thorac. Cardiovasc. Surg. 136, 1123-1130.

Sakai, T., Johnson, K. J., Murozono, M., Sakai, K., Magnuson, M. A., Wieloch, T., Cronberg, T., Isshiki, A., Erickson, H. P. and Fässler, R. (2001). Plasma fibronectin supports neuronal survival and reduces brain injury following transien focal cerebral ischemia but is not essential for skin-wound healing and hemostasis. Nat. Med. 7, 324-330.

Schwartz, M. A. (2010). Integrins and extracellular matrix in mechanotransduction Cold Spring Harb. Perspect. Biol. 2, a005066.

Schwartz, M. A. and Assoian, R. K. (2001). Integrins and cell proliferation: regulation of cyclin-dependent kinases via cytoplasmic signaling pathways. J. Cell Sci. 114, 2553-2560.
Serres, E., Debarbieux, F., Stanchi, F., Maggiorella, L., Grall, D., Turchi, L., Burel-Vandenbos, F., Figarella-Branger, D., Virolle, T., Rougon, G. et al. (2014). Fibronectin expression in glioblastomas promotes cell cohesion, collective invasion of basement membrane in vitro and orthotopic tumor growth in mice. Oncogene 33, 3451-3462.

Shi, F., Long, X., Hendershot, A., Miano, J. M. and Sottile, J. (2014). Fibronectin matrix polymerization regulates smooth muscle cell phenotype through a Rac1 dependent mechanism. PLoS ONE 9, e94988.

Soriano, P. (1999). Generalized lacZ expression with the ROSA26 Cre reporter strain. Nat. Genet. 21, 70-71.

Stenzel, D., Lundkvist, A., Sauvaget, D., Busse, M., Graupera, M., van der Flier, A., Wijelath, E. S., Murray, J., Sobel, M., Costell, M. et al. (2011). Integrindependent and -independent functions of astrocytic fibronectin in retinal angiogenesis. Development 138, 4451-4463.

Stoller, J. Z. and Epstein, J. A. (2005). Cardiac neural crest. Semin. Cell Dev. Biol. 16, 704-715.

Stottmann, R. W. and Klingensmith, J. (2011). Bone morphogenetic protein signaling is required in the dorsal neural folds before neurulation for the induction of spinal neural crest cells and dorsal neurons. Dev. Dyn. 240, 755-765.

Stottmann, R. W., Choi, M., Mishina, Y., Meyers, E. N. and Klingensmith, J. (2004). BMP receptor IA is required in mammalian neural crest cells fo development of the cardiac outflow tract and ventricular myocardium. Development 131, 2205-2218.

Takahashi, S., Leiss, M., Moser, M., Ohashi, T., Kitao, T., Heckmann, D., Pfeifer, A., Kessler, H., Takagi, J., Erickson, H. P. et al. (2007). The RGD motif in fibronectin is essential for development but dispensable for fibril assembly. J. Ce/l Biol. 178, 167-178.

Tang, Y., Urs, S. and Liaw, L. (2008). Hairy-related transcription factors inhibit Notch-induced smooth muscle alpha-actin expression by interfering with Notch intracellular domain/CBF-1 complex interaction with the CBF-1-binding site. Circ. Res. 102, 661-668.

Testaz, S., Delannet, M. and Duband, J. (1999). Adhesion and migration of avian neural crest cells on fibronectin require the cooperating activities of multiple integrins of the (beta)1 and (beta)3 families. J. Cell Sci. 112, 4715-4728.

Trainor, P. and Krumlauf, R. (2000). Plasticity in mouse neural crest cells reveals a new patterning role for cranial mesoderm. Nat. Cell Biol. 2, 96-102.

Trainor, P. A., Ariza-McNaughton, L. and Krumlauf, R. (2002a). Role of the isthmus and FGFs in resolving the paradox of neural crest plasticity and prepatterning. Science 295, 1288-1291.

Trainor, P. A., Sobieszczuk, D., Wilkinson, D. and Krumlauf, R. (2002b) Signalling between the hindbrain and paraxial tissues dictates neural crest migration pathways. Development 129, 433-442.

Turlo, K. A., Noel, O. D. V., Vora, R., LaRussa, M., Fassler, R., Hall-Glenn, F. and Iruela-Arispe, M. L. (2012). An essential requirement for beta1 integrin in the assembly of extracellular matrix proteins within the vascular wall. Dev. Biol. 365 , 23-35

Turner, C. J., Badu-Nkansah, K., Crowley, D., van der Flier, A. and Hynes, R. O. (2014). Integrin-alpha5beta1 is not required for mural cell functions during development of blood vessels but is required for lymphatic-blood vessel separation and lymphovenous valve formation. Dev. Biol. 392, 381-392.

Turner, C. J., Badu-Nkansah, K., Crowley, D., van der Flier, A. and Hynes, R. O. (2015). alpha5 and alphav integrins cooperate to regulate vascular smooth muscle and neural crest functions in vivo. Development 142, 797-808.

Vallejo-Illarramendi, A., Zang, K. and Reichardt, L. F. (2009). Focal adhesion kinase is required for neural crest cell morphogenesis during mouse cardiovascular development. J. Clin. Invest. 119, 2218-2230.

Wasteson, P., Johansson, B. R., Jukkola, T., Breuer, S., Akyurek, L. M. Partanen, J. and Lindahl, P. (2008). Developmental origin of smooth muscle cells in the descending aorta in mice. Development 135, 1823-1832.

Watt, F. M. and Huck, W. T. S. (2013). Role of the extracellular matrix in regulating stem cell fate. Nat. Rev. Mol. Cell Biol. 14, 467-473.

Wilm, B., Ipenberg, A., Hastie, N. D., Burch, J. B. E. and Bader, D. M. (2005). The serosal mesothelium is a major source of smooth muscle cells of the gut vasculature. Development 132, 5317-5328.

Yang, J. T., Rayburn, H. and Hynes, R. O. (1993). Embryonic mesodermal defects in alpha 5 integrin-deficient mice. Development 119, 1093-1105.

Yang, J. T., Bader, B. L., Kreidberg, J. A., Ullman-Cullere, M., Trevithick, J. E. and Hynes, R. O. (1999). Overlapping and independent functions of fibronectin receptor integrins in early mesodermal development. Dev. Biol. 215, 264-277.

Yashiro, K., Shiratori, H. and Hamada, H. (2007). Haemodynamics determined by a genetic programme govern asymmetric development of the aortic arch. Nature 450, 285-288

Yoshino, T., Saito, D., Atsuta, Y., Uchiyama, C., Ueda, S., Sekiguchi, K. and Takahashi, Y. (2014). Interepithelial signaling with nephric duct is required for the formation of overlying coelomic epithelial cell sheet. Proc. Natl. Acad. Sci. USA 111, 6660-6665

Yurchenco, P. D. (2011). Basement membranes: cell scaffoldings and signaling platforms. Cold Spring Harb. Perspect. Biol. 3, a004911. 